\title{
Lagrangian Observations of the Middepth and Deep Velocity Fields of the Northeastern Atlantic Ocean
}

\author{
MatThias LANKHORST AND WALTER ZeNK \\ Leibniz-Institut für Meereswissenschaften (IFM-GEOMAR), Kiel, Germany
}

(Manuscript received 8 November 2004, in final form 6 July 2005)

\begin{abstract}
The circulation of the northeastern Atlantic Ocean at intermediate depths is characterized by watermass transformation processes that involve Iceland-Scotland Overflow Water (ISOW) from the northeast, Labrador Sea Water (LSW) from the west, and Mediterranean Water from the south. Field observations were carried out with 89 eddy-resolving floats (RAFOS and MARVOR types). The data coverage achieved is remarkably high and enables a comprehensive study of the eastern basins between Iceland and the Azores. The trajectories show typical pathways of the water masses involved and the role that the complex bottom topography plays in defining them. The ISOW paths tend to lean against the slopes of the Reykjanes Ridge and Rockall Plateau. Westward escapes through multiple gaps in the ridge are possible, superimposed on a sustained southward flow in the eastern basin along the Mid-Atlantic Ridge. LSW pathways leading to the eastern basins are subject to high variability in flow direction and eddy activity. In addition to a selection of characteristic trajectories, maps of the horizontal distributions of Lagrangian eddy kinetic energy and integral time scales are presented. These reveal distinct areas of intensified mixing in the Iceland Basin, as well as the sharp contrast between the subpolar and subtropical dynamics. A self-contained eddy detection scheme is applied to obtain statistics on individual eddy properties and their abundance. It is suggested that much of the intensified mixing can be related to cyclonic activity, particularly in the subpolar region.
\end{abstract}

\section{Introduction}

The circulation of the eastern North Atlantic Ocean as a whole is an integral part of the global thermohaline circulation. Superimposed on the circulation of the subpolar and subtropical gyres, warm Atlantic surface waters are exported into the Nordic seas and the transformed colder overflow waters are reimported simultaneously. The latter represents an important admixture of North Atlantic Deep Water (NADW) invading the World Ocean by the interconnecting Southern Ocean on decadal or centennial scales (Schmitz 1995).

Early understandings of the North Atlantic circulation date back at least to the monograph by HellandHansen and Nansen (1909) on the physical oceanography of the Norwegian Sea. This benchmark book already emphasizes the importance of the IcelandScotland Ridge for the exchange of water masses be-

Corresponding author address: Matthias Lankhorst, LeibnizInstitut für Meereswissenschaften (IFM-GEOMAR), Düsternbrooker Weg 20, 24105 Kiel, Germany.

E-mail: mlankhorst@ifm-geomar.de tween the open Atlantic and the Norwegian Sea. Almost a century later, the extended essay by Hansen and Østerhus (2000) reviews the transformation of warm Atlantic surface waters that return southward as cold overflows back from the Nordic seas. The authors accumulate numerous details of the Iceland-Scotland Overflow Water (ISOW) describing its origin and spreading over and beyond the separating ridges and channels. The main features of the complex topography of the study area are highlighted on Fig. 1. ISOW consists of a blend of Norwegian Sea Arctic Intermediate Water and Norwegian Sea Deep Water lying in the buffer region just north of the Iceland-Scotland Ridge. This mixing product ISOW, as well as its western companion Denmark Strait Overflow Water (DSOW), seeks its way as a contour current, strongly guided by local topography. While spreading westward through Faroe Bank Channel (FBC) toward the Reykjanes Ridge (RR) and farther southwestward, the original ISOW is entrained by other water masses vertically and horizontally. This transformation process is supposed to enlarge the ISOW mass transport by a factor of 2-3 (van Aken and Becker 1996). At the same time, ISOW 


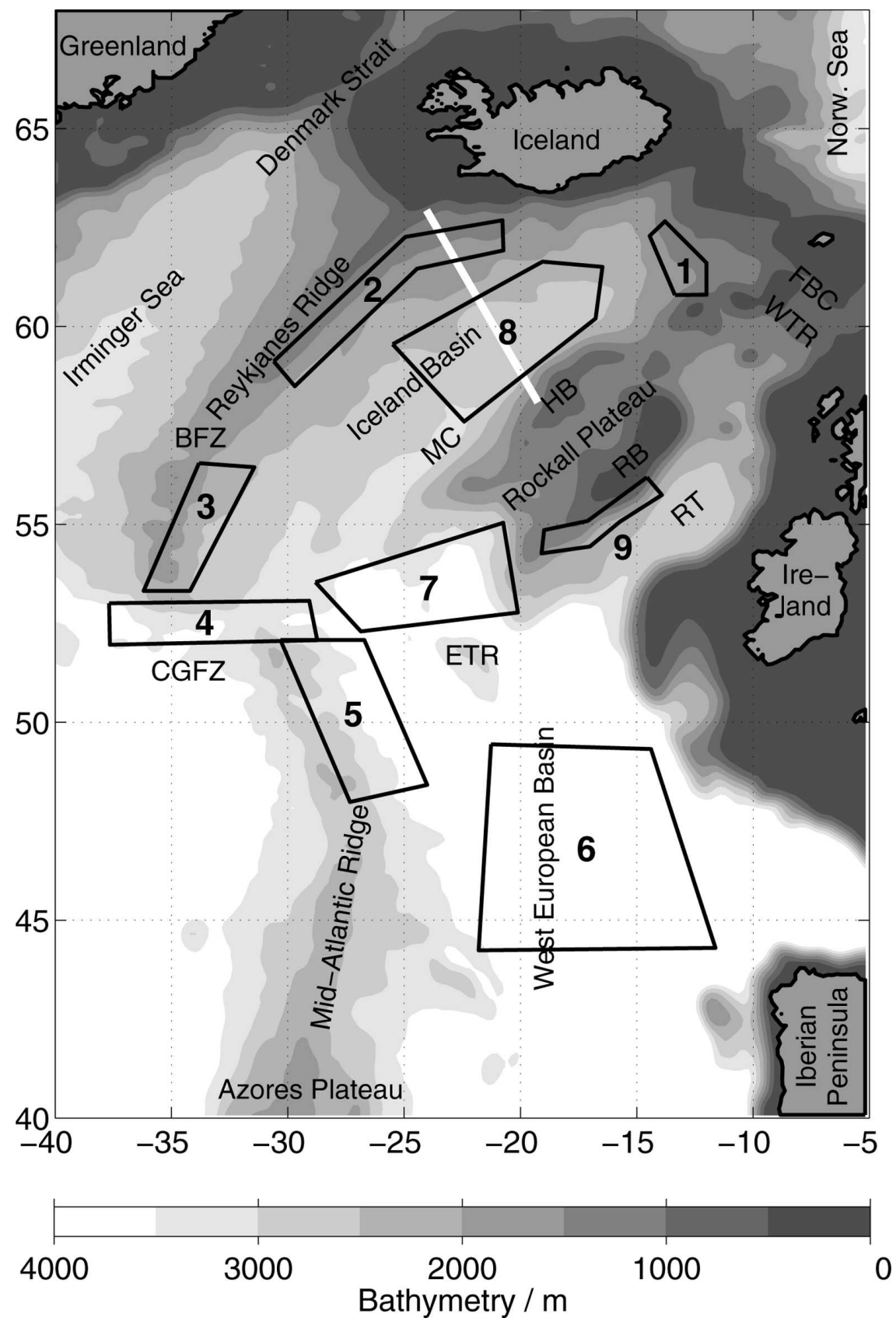

FIG. 1. Geographic map of the northeastern Atlantic. Numbered polygons refer to dynamically different regions discussed in section 3. Abbreviations of geographic names are Bight Fracture Zone (BFZ), Charlie-Gibbs Fracture Zone (CGFZ), East Thulian Rise (ETR), Faroe Bank Channel (FBC), Hatton Bank (HB), Maury Channel (MC), Rockall Bank (RB), Rockall Trough (RT), and Wyville-Thomson Ridge (WTR). The white line through the Iceland Basin shows the location of the CTD section of Fig. 11.

is converted from a density current into an intermediate-depth jet, an analogous process happening in the western Gulf of Cadiz with the Mediterranean Sea outflow (Bower et al. 2002b).

The accommodating region in the central Iceland $\mathrm{Ba}-$ sin hosts a variety of other water masses. The slightly salt-enriched ISOW encounters much fresher Labrador Sea Water (LSW) at an intermediate depth. The latter originates from deep wintertime convection in the westernmost extent of the subpolar North Atlantic. One of 
three identified pathways (Sy et al. 1997; Paillet et al. 1998; Fischer and Schott 2002) imports freshly generated LSW on a zonal course through the Charlie-Gibbs Fracture Zone (CGFZ) directly into the Iceland Basin. Remainders of Mediterranean Water can also be traced at least near the southeastern exit of the Iceland Basin. A weak eastern boundary current carries it from Gibraltar up to the flank of the Porcupine Bank off the Irish shelf (Bower et al. 2002b). The Lower Deep Water (LDW) flows between LSW and remainders of Antarctic Bottom Water (AABW) farther to the south $\left(40^{\circ} \mathrm{N}\right)$. It contains admixtures of modified ISOW that have made their way substantially below the LSW level where they follow a sparsely defined cyclonic circulation pattern (McCartney 1992; van Aken and Becker 1996). Particularly in regions where the Iceland Basin is shallower than $3000 \mathrm{~m}$, LDW occupies the bottom layer. The spreading of AABW with potential temperatures below $2^{\circ} \mathrm{C}$ ends at the latitude of southern Portugal at the Discovery Gap (Saunders 1987).

Two additional paths of LSW beyond CGFZ must be considered, other than the northern branch filling the Iceland Basin via the Maury Channel (MC). In Fig. 2, the general circulation at intermediate depth as observed by the respectable number of 85 RAFOS and MARVOR float years (included in this study) is redisplayed (taken from Bower et al. 2002a). The high density of streamlines in the CGFZ emphasizes the increased flow speed of LSW through CGFZ. In addition, its eastern extension clearly indicates a secondary pathway following the eastern side of the Mid-Atlantic Ridge (MAR) southward as an intermediate western boundary current (Fleischmann et al. 2001; Machín et al. 2006). A third branch deviates southeastward with distinctly weaker flow toward the central West European Basin. It approaches the Iberian Basin, directly encountering the tongue of Mediterranean Water (Hinrichsen et al. 1993). The mean currents have been mapped recently by Faure and Speer (2005) with a greater float dataset, confirming the above points.

As already pointed out by Hansen and Østerhus (2000), the nomenclature of water masses of the eastern North Atlantic is complex and confusing. The most recent and sophisticated layer definitions are those by Lorbacher (2000) and Lumpkin and Speer (2003). In both cases, the authors use neutral density layers $\gamma^{n}$ for their (unfortunately nonuniform) classifications. For instance, LSW is either defined in the range $27.90<\gamma^{n}<$ 27.99 at a mean pressure level of 1500 dbar or $27.879<$ $\gamma^{n}<27.976$ at 1457 dbar, respectively.

As an additional introductory reference, Fig. 3 (adapted from Hansen and Østerhus 2000) schematically displays the main overflow features and pathways in the subpolar North Atlantic. The diagram is generally consistent with direct observations in Fig. 2 representing a first-order view of the mean circulation at middepth. The entrained ISOW follows the eastern flank of the RR down to about $60^{\circ} \mathrm{N}$ where two divergences north of and at CGFZ are shown. This water can partially escape through these gaps in the MAR [i.e., Bight and Charlie-Gibbs Fracture Zones in Bower et al. (2002a)]. As confirmed by Fig. 2, residues proceed beyond CGFZ and reach the West European Basin. Hansen and Østerhus (2000) indicate two additional direct overflow pathways connecting the exit of the Iceland-Scotland Ridge with the MC on the western flank of the Rockall Plateau (RP) and with Rockall Trough (RT) on its eastern flank. These two near-bottom paths are subject to great uncertainties because they compete immediately with LSW.

In this paper, a series of Lagrangian observations, collected in a depth range between 1500 and $2600 \mathrm{~m}$ over a period of $7 \mathrm{yr}$ (1996-2003), is presented. The majority of trajectories originate from the layer depth of LSW (i.e., around $1500 \mathrm{~m}$ ). Other water masses traced are ISOW and LDW, whereas the Mediterranean Water is not included in this analysis, because it is mainly at shallower depths and beyond the southeastern border of the area with reasonable data coverage. The measurements were initiated in the early 1990s by the Eurofloat consortium and were enhanced by the German accelerated research initiative (Sonderforschungsbereich) SFB 460, Dynamics of Thermohaline Circulation Variability, at the Institut für Meereskunde in Kiel, Germany [now Leibniz-Institut für Meereswissenschaften (IFM-GEOMAR)]. One goal of the latter is to document the pathways, mean flow, and flow variability of water parcels in the Iceland Basin, given the expectation that this is a region of fairly intense transformation of the water masses previously described. The mean flow derived from these data has already been discussed in the short article by Bower et al. (2002a); this current work presents discussions of individual trajectories and the eddy field that could not be dealt with in that paper. In particular, the question marks in Fig. 3 are addressed, and the maps of the mesoscale eddy parameters by Lumpkin et al. (2002) are substantially enlarged to include the subpolar regions.

Section 2 contains details on the observational strategy and introduces the Lagrangian dataset with supplementary CTD data. In section 3, the main characteristics of nine selected regions are presented and individual trajectories are discussed. The mesoscale eddy field is described in section 4, covering eddy kinetic energy and associated time scales. An attempt is made 


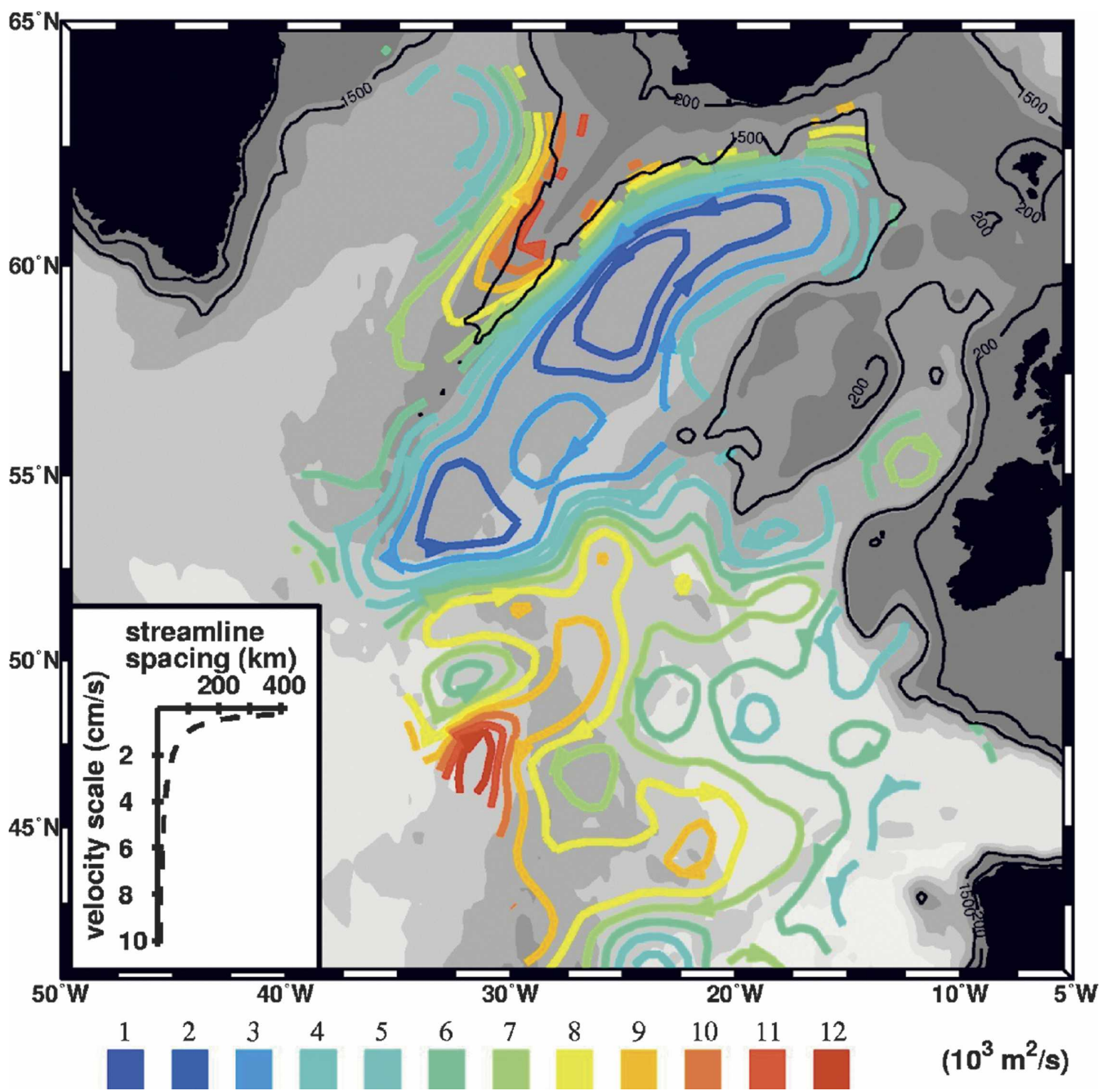

FIG. 2. Streamfunction at $1500-1750 \mathrm{~m}$ in the northeastern Atlantic derived from RAFOS and MARVOR float data. Figure taken from Bower et al. (2002a), with permission from Nature Publishing Group. Colors refer to volume transport per unit layer thickness according to the scale given. Direct velocity can be inferred from streamline spacing with the legend.

to relate these quantities to the properties of autodetected individual eddy events. A conclusions section and an appendix with computational details follow.

\section{Methods and datasets}

One of the primary tools in approaching the SFB goal to investigate fluctuations of watermass formation and transport processes is Lagrangian observations in the Iceland Basin area. Between 1997 and 2002, the region was revisited six times with research vessels (see Table 1). Besides repeated hydrography, 68 nearly isobaric (i.e., significantly less compressible than the surrounding water) RAFOS floats were launched. An overview of this float dataset is presented online by Lankhorst et al. (2004). At the beginning of the SFB work, the middepth circulation in the region south of CGFZ was already under investigation by the northern component of Eurofloat (Speer et al. 1999; Sparrow et al. 2002). These data up to 2001 were kindly made avail- 


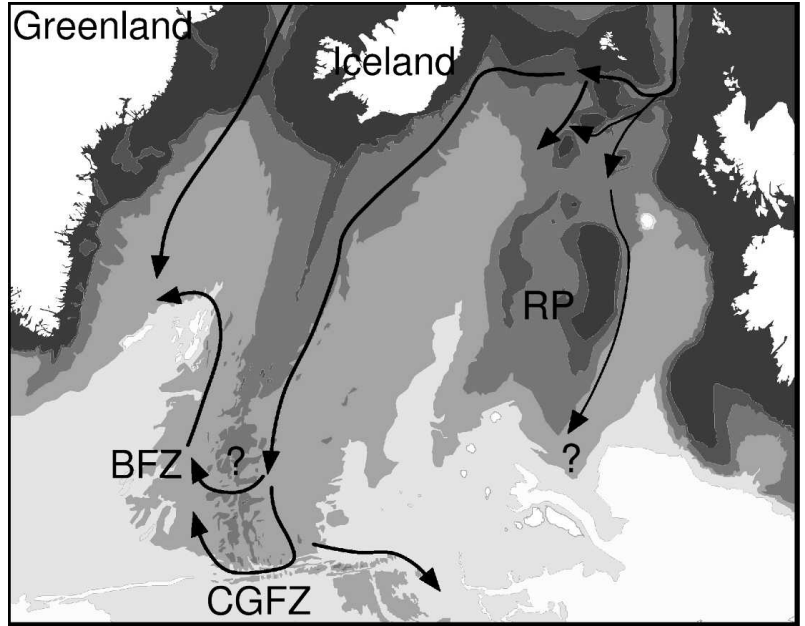

FIG. 3. Schematic of overflow pathways from the Arctic Sea into the North Atlantic. Figure extract adapted from Hansen and Østerhus (2000, p. 119), (C2000, with permission from Elsevier. Abbreviations of geographic names are given in Fig. 1 caption. The two question marks (one at BFZ, the other south of RP) are addressed in the present study.

able by B. le Cann of Brest, France (B. le Cann 2004, personal communication; Bower et al. 2002a). Figure 4 displays a sum of all float activities separated by SFB and Eurofloat, their launch times, nominal depths, and mission lengths. The float drift depths were chosen to agree with the averaged watermass levels, that is, 1500 and $1750 \mathrm{dbar}$ with respect to LSW north and south of CGFZ, and 2600 dbar concentrated in the LDW of the Iceland Basin. (This information is also shown in Fig. 11, described below, in which the pressure records of the floats in the northeastern Iceland Basin are projected onto a recent hydrographic section. All floats used are acoustically tracked and record underwater positions once per day.)

In contrast to RAFOS floats (for method, see Rossby et al. 1986a and Ollitrault 1999), MARVORs as used during the Eurofloat campaign return to the surface multiple times, in this case every 3 months [for a comparison of different float models and insonification de-

TABLE 1. Summary of ship cruises with RAFOS float launches in the Iceland Basin during the SFB $460 \mathrm{~A} 3$ project.

\begin{tabular}{lllc}
\hline \hline Ship, cruise leg & \multicolumn{1}{c}{ Departure } & \multicolumn{1}{c}{ Arrival } & $\begin{array}{c}\text { No. of float } \\
\text { deployments }\end{array}$ \\
\hline Meteor 39/2 & 15 May 1997 & 8 Jun 1997 & 17 \\
Poseidon 242 & 2 Aug 1998 & 21 Aug 1998 & 22 \\
Meteor 45/2 & 10 Jun 1999 & 9 Jul 1999 & 8 \\
Poseidon 261 & 27 Jun 2000 & 14 Jul 2000 & 10 \\
Meteor 50/4 & 18 Jul 2001 & 12 Aug 2000 & 8 \\
Poseidon 293/1 & 7 Jul 2002 & 14 Jul 2002 & 3 \\
\hline
\end{tabular}

vices, see Davis and Zenk (2001)]. In this analysis, every Eurofloat cycle is treated as a separate float trajectory, thus avoiding congestion with surface drifts during their up times. As in the work by Owens (1991) on the circulation in the northwestern North Atlantic, no attempts have been made to correct float velocities to a common nominal depth level. The longest RAFOS mission of the SFB experiment was 928 days long, while MARVOR floats have been reported to last up to $5 \mathrm{yr}$. Thus, a combination of successive partial MARVOR trajectories yielded the longest quasi-continuous record of almost one-half of a decade (Fig. 10c, described later in the paper).

The observations with SFB and Eurofloat floats lasted from September of 1996 through September of 2003. At the end of this period, a new float type became increasingly popular: as a component of the newly launched global project Argo and with support by the European Union (project "Gyroscope"), 84 cycling floats with capabilities to measure temperature and salinity profiles between $2000 \mathrm{~m}$ and the surface were launched in the North Atlantic. In contrast to MARVORs, these floats cannot utilize RAFOS acoustic signals. Therefore they sample no daily underwater positions. Instead, their in situ drifts can only be estimated from surface fixes 10 days apart. In the case of Gyroscope, the missions started between July of 2001 and September of 2002, and the data are freely available on the Internet.

Figure 5 provides information on the regional data densities. The main area of interest, the Iceland Basin, has float densities exceeding 400 float days per $1.5^{\circ} \times$ $2^{\circ}$ (latitude-longitude) box. Figure 6 shows a spaghetti plot of the SFB and Eurofloat instruments, with the Argo data available until October of 2004 superimposed. In most cases the instruments were seeded along straight cruise lines preferably orthogonal to the local bathymetry. The floats quickly dispersed over most of the eastern basins from the Iceland-Scotland Ridge to the Azores Plateau. The constraining character of the MAR for the spreading of intermediate and deep water masses is obvious. Nevertheless, a few floats were advected westward through fracture zones. Their escapes from the eastern basins extend the SFB dataset into the deep East Greenland Current (upper-left corner in Fig. 6) and even farther into the Labrador Sea (not shown). There is also surprisingly little exchange between the subpolar (mainly sampled by SFB floats) and subtropical (mainly Eurofloat) regimes.

\section{Characteristic pathways in selected regions}

The basinwide middepth circulation of the Iceland Basin is a cyclonic motion fed by two driving jets: one 


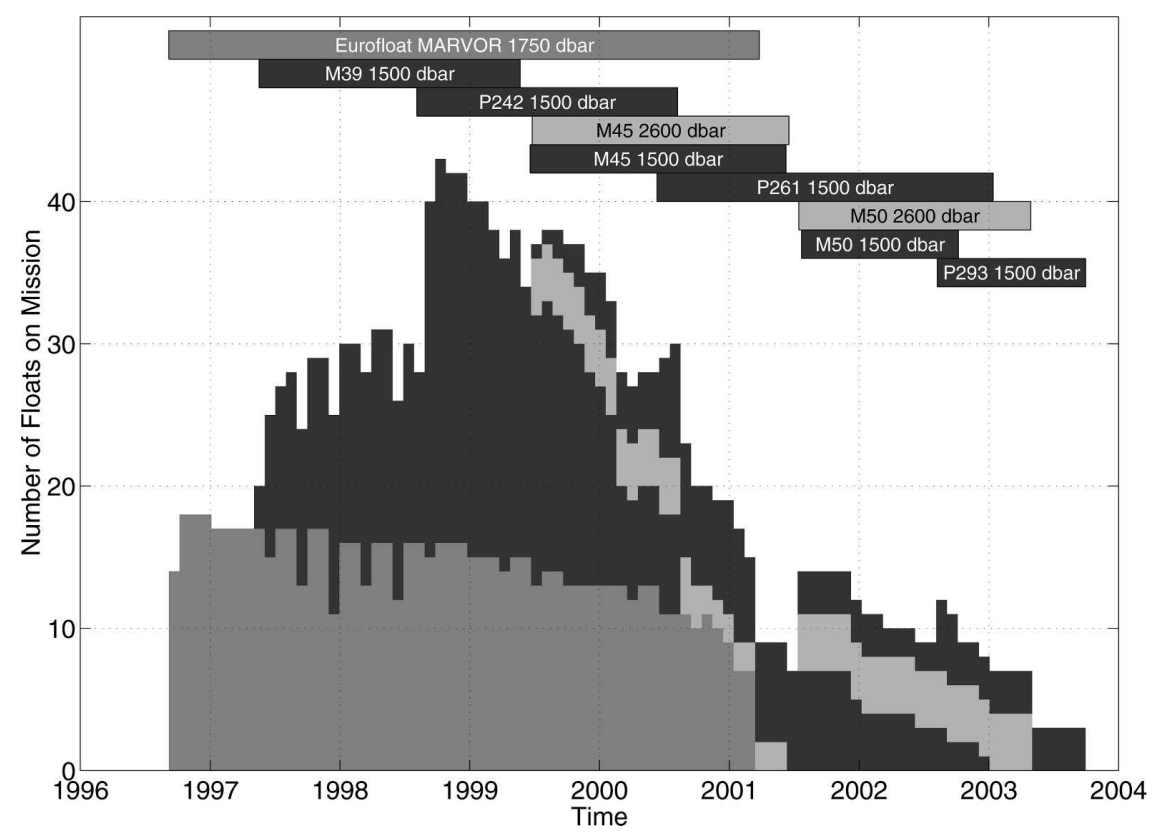

FIG. 4. Overview of float missions from SFB RAFOS and Eurofloat MARVOR floats. A few Eurofloat missions lasted even longer than shown here. Different gray shades indicate different launch cruises and target depths as described in the top part of the figure [Meteor (M) and Poseidon (P) cruises; cf. Table 1).

consists of ISOW entering at the northeastern tip and the other of LSW invading the basin in the southwest (blue and cyan streamlines in Fig. 2). Following this cyclonic circulation, nine selected regions (shown in Fig. 1) are discussed in this section. For each region, the main features derived from our rich Lagrangian database with its unprecedented spatial resolution are presented, but the focus of these descriptions obviously has to vary depending on the characteristics of the regions. The reader is reminded that the mean flow derived from the data has already been discussed by Faure and Speer (2005) and Bower et al. (2002a; cf. Fig. 2), and that corresponding maps of the mesoscale field follow in section 4.

Region 1 is the "impact" area where newly formed ISOW first enters the Iceland Basin at the exit of the FBC. Once the floats get into the overflow path, they are rapidly ejected from this region to the northwest, parallel to the isobaths. Floats entering this region show its frontal character most clearly by sudden changes in their temperature records: one instrument measured a drop of almost $2 \mathrm{~K}$ over 15 days, followed by another temperature drop from $3.87^{\circ}$ to $2.54^{\circ} \mathrm{C}$ within 3 days. Such low temperatures are indicative of large concentrations of ISOW near the bottom. For instance, van Aken and de Boer (1995) report admixtures of more than $80 \%$ ISOW with temperatures below $2.5^{\circ} \mathrm{C}$ on a hydrographic section along $17^{\circ} \mathrm{W}$ south of Iceland.
Probably an equal amount of one or two entrained LSW filaments [more than 50\% according to van Aken and de Boer (1995)] was recorded only 3 and 14 days later with temperatures above $4.2^{\circ} \mathrm{C}$ at $1480 \mathrm{dbar}$. It should be noted that although the floats drift approximately horizontally, vertical displacements of course happen when floats encounter horizontal density gradients as in these cases, with observed vertical float excursions of $O(100) \mathrm{m}$. More on vertical float motions has been published by Rossby (1988) and Swift and Riser (1994).

Region 2 along the ISOW pathway is situated on the eastern flanks of the RR. On the basis of surface drifters and a hydrographic survey, a downward entrainment of $0.5 \mathrm{~Sv}\left(1 \mathrm{~Sv} \equiv 10^{6} \mathrm{~m}^{3} \mathrm{~s}^{-1}\right)$ at $62^{\circ} \mathrm{N}$ (center of region 2) was calculated by Krauss (1995). This volume increases the flux of $2.8 \mathrm{~Sv}$ of cold bottom water entering the Iceland Basin via the FBC. Hence, the consolidated overflow [ $-3.3 \mathrm{~Sv}$ according to Fig. 9 in Krauss (1995)] moves swiftly westward and later southwestward following the RR (van Aken and de Boer 1995; van Aken and Becker 1996). Our float observations confirm this directly and show very straight trajectories parallel to the isobaths. Table 2 contains kinematic properties from our float observations of the region (and others to follow). Typical velocities near $25^{\circ} \mathrm{W}$ are $10 \mathrm{~cm}^{-1}$, with peaks exceeding 2 times this value. The persistent character of the contour current is docu- 


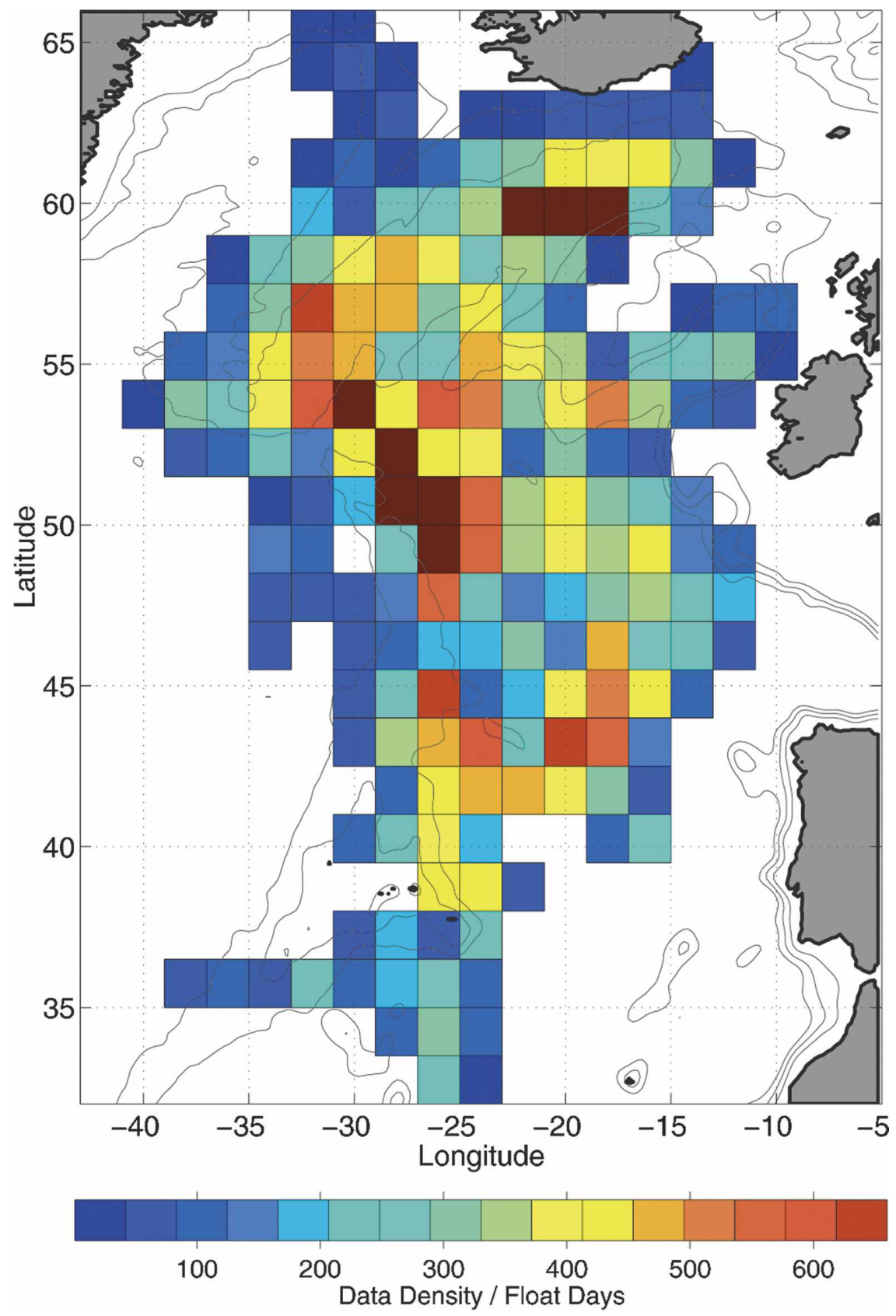

FIG. 5. Data density in boxes of $1.5^{\circ} \times 2^{\circ}$ lat-lon. Note that in the interior Iceland and West European Basins, data densities reach remarkably high values, exceeding 400 float days throughout most of the area. Dark red colors denote values beyond the color scale at the bottom. Gray lines indicate smoothed isobaths at 1000, 2000, and $3000 \mathrm{~m}$.

mented in its high vector stability $(>90 \%) .{ }^{1}$ Little or no meandering of trajectories is found in region 2, leading to this unusually high ratio of mean to eddy kinetic energy.

\footnotetext{
${ }^{1}$ Vector stability is defined as the ratio of the means of $u_{\|}$and $|(u, v)|$ given in Table 2.
}

Region 3 covers the lower RR south of circa $58^{\circ} \mathrm{N}$ and north of CGFZ $\left(52^{\circ} \mathrm{N}\right)$. The depth of the whole ridge system increases systematically (from circa 1000 $\mathrm{m}$ at $60^{\circ} \mathrm{N}$ to $1600 \mathrm{~m}$ just north of CGFZ, i.e., eventually beneath the average float level). The RR appears increasingly perforated, allowing easier exchange across the rift valley and the neighboring basins on both sides 


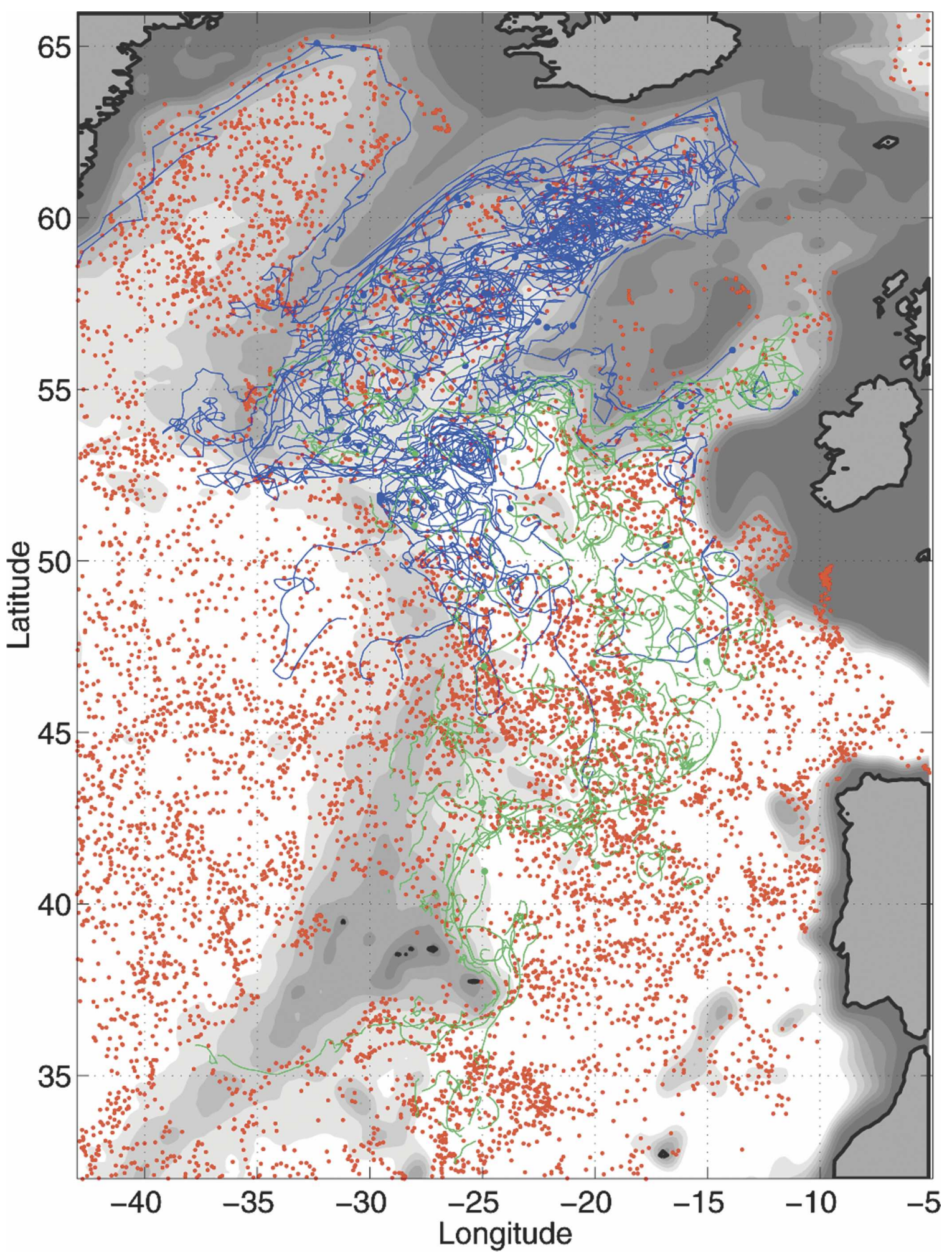

FIG. 6. Summary plot of all float trajectories used in this study (spaghetti plot). Blue and green trajectories are from SFB RAFOS and Eurofloat MARVOR floats, respectively. Red dots mark all profile positions from floats of the Argo array available until October of 2004. Bathymetry is as in Fig. 1. 
TABLE 2. Statistics of float velocities $\left(\mathrm{cm} \mathrm{s}^{-1}\right)$ in the regions shown in Fig. 1. Minimum, maximum, mean, median, and standard deviation are displayed for zonal and meridional velocities $u$ and $v$, for scalar horizontal velocity $|(u, v)|$, and for a coordinate system rotated to yield velocity components along $\left(u_{\|}\right)$and across $\left(u_{\perp}\right)$ the mean velocity.

\begin{tabular}{|c|c|c|c|c|c|}
\hline & Min & Max & Mean & Median & Std dev \\
\hline \multicolumn{6}{|c|}{ Region 1} \\
\hline$u$ & -43.73 & 27.11 & 1.36 & 4.98 & 15.69 \\
\hline$v$ & -30.26 & 51.82 & 7.29 & 4.58 & 18.84 \\
\hline$|(u, v)|$ & 3.06 & 67.81 & 20.89 & 17.41 & 14.45 \\
\hline$u_{\|}$ & -24.77 & 42.91 & 7.42 & 5.42 & 16.45 \\
\hline$u_{\perp}$ & -32.20 & 52.50 & -0.00 & -3.68 & 18.17 \\
\hline \multicolumn{6}{|c|}{ Region 2} \\
\hline$u$ & -22.31 & 3.53 & -7.68 & -7.48 & 4.55 \\
\hline$v$ & -25.33 & 10.61 & -6.66 & -6.73 & 5.50 \\
\hline$|(u, v)|$ & 1.08 & 28.13 & 11.21 & 11.03 & 5.35 \\
\hline$u_{\|}$ & -3.23 & 27.82 & 10.16 & 10.06 & 5.69 \\
\hline$u_{\perp}$ & -14.99 & 13.01 & -0.00 & 0.48 & 4.31 \\
\hline \multicolumn{6}{|c|}{ Region 3} \\
\hline$u$ & -17.66 & 13.79 & -1.73 & -1.57 & 3.85 \\
\hline$v$ & -16.38 & 13.06 & -2.28 & -2.18 & 3.96 \\
\hline$|(u, v)|$ & 0.15 & 18.45 & 5.32 & 4.80 & 3.22 \\
\hline$u_{\|}$ & -10.62 & 16.35 & 2.86 & 2.77 & 4.00 \\
\hline$u_{\perp}$ & -14.41 & 16.92 & -0.00 & 0.04 & 3.81 \\
\hline \multicolumn{6}{|c|}{ Region 4} \\
\hline$u$ & -22.11 & 33.14 & 3.80 & 2.98 & 8.65 \\
\hline$v$ & -29.45 & 20.89 & 0.12 & 0.02 & 7.11 \\
\hline$|(u, v)|$ & 0.32 & 44.33 & 9.64 & 7.86 & 6.84 \\
\hline$u_{\|}$ & -22.18 & 32.22 & 3.80 & 3.03 & 8.63 \\
\hline$u_{\perp}$ & -30.45 & 20.99 & -0.00 & -0.10 & 7.13 \\
\hline \multicolumn{6}{|c|}{ Region 5} \\
\hline$u$ & -7.05 & 13.45 & 0.57 & 0.43 & 2.74 \\
\hline$v$ & -10.55 & 10.84 & -0.77 & -0.76 & 2.63 \\
\hline$|(u, v)|$ & 0.10 & 13.45 & 3.36 & 3.03 & 2.01 \\
\hline$u_{\|}$ & -9.24 & 11.90 & 0.96 & 0.92 & 2.78 \\
\hline$u_{\perp}$ & -8.60 & 12.14 & -0.00 & -0.17 & 2.59 \\
\hline \multicolumn{6}{|c|}{ Region 6} \\
\hline$u$ & -16.21 & 17.34 & 0.38 & 0.15 & 3.28 \\
\hline$v$ & -21.24 & 16.60 & -0.66 & -0.67 & 3.47 \\
\hline$|(u, v)|$ & 0.01 & 22.36 & 3.88 & 3.20 & 2.88 \\
\hline$u_{\|}$ & -17.49 & 21.43 & 0.76 & 0.66 & 3.43 \\
\hline$u_{\perp}$ & -20.57 & 16.04 & 0.00 & -0.11 & 3.32 \\
\hline \multicolumn{6}{|c|}{ Region 7} \\
\hline$u$ & -14.77 & 24.13 & 0.51 & 0.26 & 5.06 \\
\hline$v$ & -24.28 & 35.10 & 0.02 & 0.36 & 5.87 \\
\hline$|(u, v)|$ & 0.17 & 36.63 & 6.55 & 5.79 & 4.17 \\
\hline$u_{\|}$ & -14.70 & 23.60 & 0.51 & 0.28 & 5.01 \\
\hline$u_{\perp}^{\prime \prime}$ & -24.39 & 35.53 & 0.00 & 0.33 & 5.91 \\
\hline \multicolumn{6}{|c|}{ Region 8} \\
\hline$u$ & -31.31 & 42.50 & 0.49 & -0.36 & 9.23 \\
\hline$v$ & -25.80 & 40.96 & 0.39 & 0.08 & 7.93 \\
\hline$|(u, v)|$ & 0.14 & 49.46 & 10.16 & 8.71 & 6.74 \\
\hline$u_{\|}$ & -33.43 & 41.06 & 0.62 & -0.32 & 8.86 \\
\hline$u_{\perp}$ & -46.21 & 33.09 & -0.00 & 0.38 & 8.35 \\
\hline \multicolumn{6}{|c|}{ Region 9} \\
\hline$u$ & -19.36 & 23.53 & -2.34 & -1.75 & 4.32 \\
\hline$v$ & -15.52 & 16.98 & -0.77 & -0.46 & 3.58 \\
\hline$|(u, v)|$ & 0.08 & 25.11 & 4.45 & 3.73 & 4.21 \\
\hline$u_{\|}$ & -19.61 & 21.93 & 2.46 & 1.54 & 4.57 \\
\hline$u_{\perp}$ & -15.83 & 15.70 & 0.00 & 0.14 & 3.25 \\
\hline
\end{tabular}
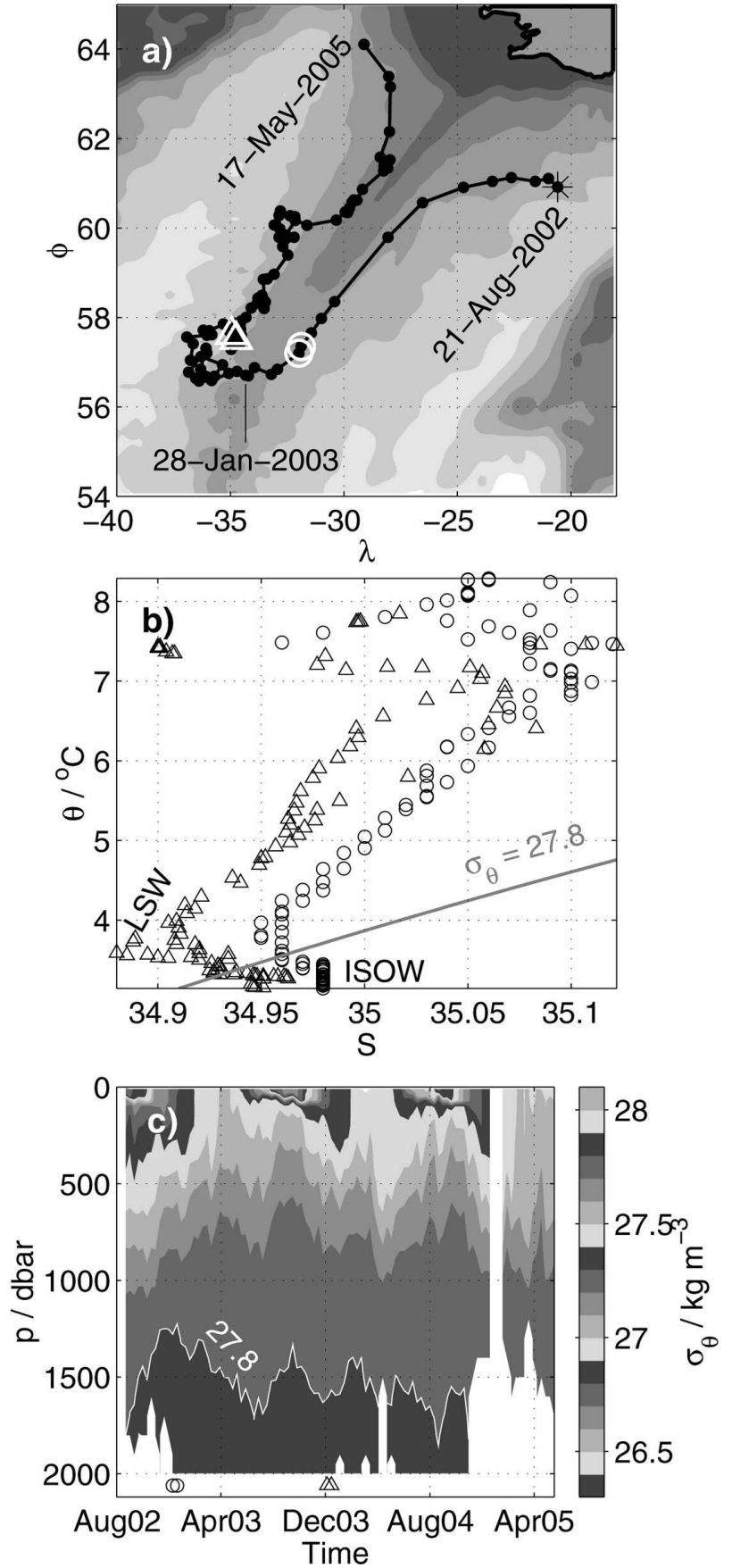

FIG. 7. Example of an Argo float (No. 6900186) crossing RR through BFZ $\left(\sim 57^{\circ} \mathrm{N}, 34^{\circ} \mathrm{W}\right)$. (a) Trajectory (bathymetry as in Fig. 1). The first position is marked by an asterisk. The profile positions are 10 days apart and are marked by interconnected black dots. White triangles and circles denote positions of four selected profiles (two on either side of the ridge). (b) The temperature-salinity diagram of these four profiles. Note how they converge at low temperatures (ISOW). Position of LSW (salinity minimum) and $\sigma_{\theta}=27.80 \mathrm{~kg} \mathrm{~m}^{-3}$ are also indicated. (c) Potential density in a "waterfall" plot. The white line highlights the value of $27.80 \mathrm{~kg} \mathrm{~m}^{-3}$, indicative of ISOW. Symbols at the bottom refer to the profiles displayed in (b). 

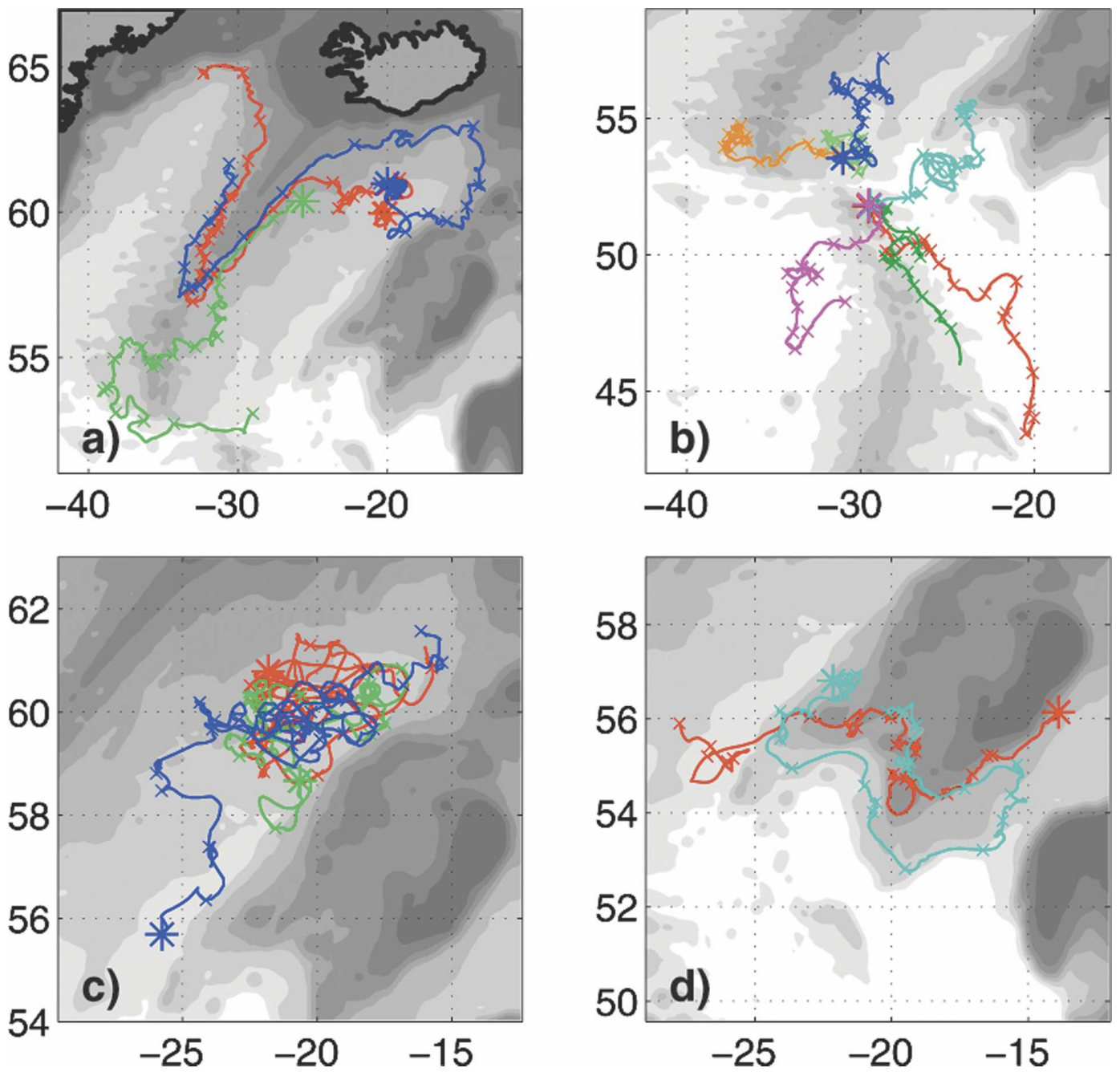

FIG. 8. Individual trajectories discussed in the text. Asterisks mark float launch positions, and additional ticks are shown every 30 days: (a) RR crossings, especially through BFZ, (b) trajectories from two float parks east of CGFZ, (c) trajectories in the central Iceland Basin, and (d) trajectories in the southern edge of RP. Bathymetry is as in Fig. 1.

of it. In agreement with the export at and south of the Bight Fracture Zone (BFZ) first described by Bower et al. (2002a), Figs. 7a and 8a compile selected trajectories from eddy-resolving RAFOS and cycling Webb Research Corporation Autonomous Profiling Explorer (APEX) floats that left the boundary current from region 2 with diluted ISOW just in this perforated area. Speeds then decrease substantially on the western side of the RR where a blend of ISOW-sometimes called GFZ Water (Schott et al. 2004) -is advected northeastward toward the northern tip of the Irminger Basin. Here it interleaves and mixes with fresh DSOW. BFZ in particular seems to be a permanent loophole for ISOW in region 3. This likelihood is documented by the number of trajectories passing through, as well as by computer simulations (R. Käse 2005, personal commu- nication). The latter show the main tongue of ISOW tracers to cross the ridge at the latitude of BFZ. Trajectories and hydrographic profiles from Argo floats (one example is shown in Fig. 7) confirm it. Therefore, the question mark in Fig. 3 (Hansen and Østerhus 2000) at BFZ may be considered obsolete.

The well-confirmed gateway in the BFZ region was unfortunately not noted by Dickson and Brown (1994) in their diligent analysis of the roots and pathways of NADW. In the marine geology literature, though, one finds indications of it $8 \mathrm{yr}$ earlier already (McCave and Tucholke 1986). Figure 9 has been compiled from three separate charts taken from (Srivastava et al. 1988). It shows sediment layer thickness from acoustic surveys in the region. The ridge region near $55.5^{\circ}-56.5^{\circ} \mathrm{N}$ is marked by an extended area of reduced sediment thick- 


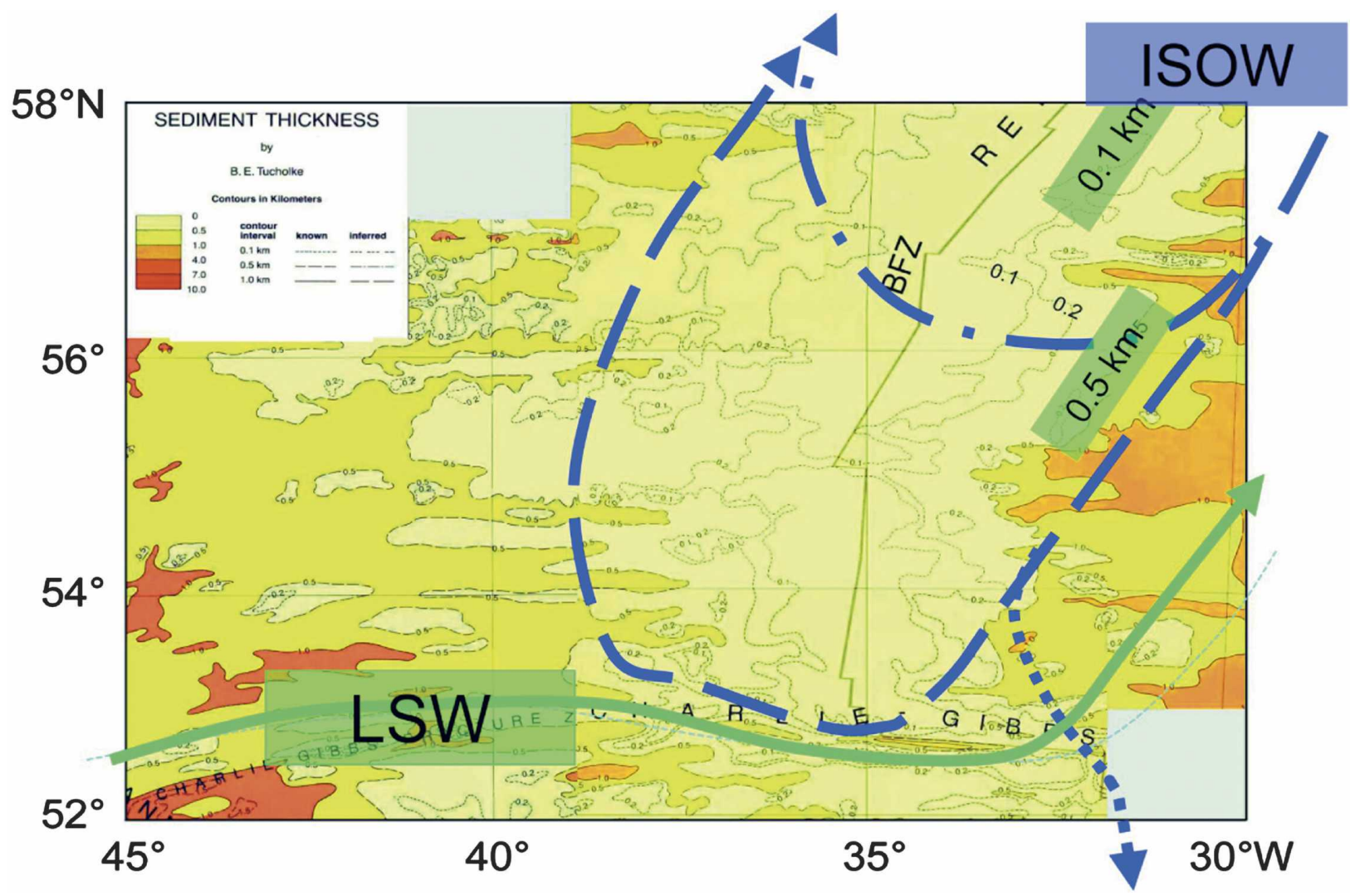

FIG. 9. Sediment thickness on the southern RR, assembled from individual charts taken from Srivastava et al. (1988, charts S-F and S-G, with permission from B. Tucholke and the Bundesamt für Seeschiffahrt und Hydrographie, Hamburg, Germany). The blue superposition shows the suggested pathways of ISOW through BFZ and CGFZ. The green arrow corresponds to the path of LSW passing through CGFZ.

ness (less than $500 \mathrm{~m}$ ) on the flanks of the RR. It is tempting to relate the reduced sediment cover near BFZ to the currents associated with this secondary overflow scenario, suggesting that the currents observed with the floats are persistent and rapid enough to prevent suspended material from deposition in the area. Float observations suggest near-bottom velocities of up to $10 \mathrm{~cm} \mathrm{~s}^{-1}$ but are perhaps underestimating the actual values because of running aground.

Figure $8 \mathrm{a}$ also contains evidence of a potentially divergent flow field west of the export gaps of region 3 : one float did not follow the Irminger cyclone; instead, it was attracted and captured by a branch of LSW progressing eastward, which reimported it back into the Iceland Basin.

The CGFZ (region 4) has long been identified as a prime exchange region for water masses across the MAR (Worthington and Volkmann 1965; Dickson and Brown 1994; Saunders 1994; Schott et al. 1999). Near $52.5^{\circ} \mathrm{N}$, the submarine promontories of the MAR are shifted eastward by approximately $350 \mathrm{~km}$. There are two separated zonal channels through this gap. The to- pographic control function of the CGFZ is clearly reflected in the interactions between the subpolar and subtropical gyres, which both seem to be attracted by this deep gap in the MAR (Bersch 1995; Rossby 1999). The float trajectories basically confirm the exchange character at intermediate depth of this region, though with occasionally alternating directions. As expected, one finds a strong eastward import of LSW most of the time (Paillet et al. 1998; Rhein et al. 2002). Typical Lagrangian intermediate velocities are near 10$20 \mathrm{~cm} \mathrm{~s}^{-1}$. On average, these observations are not incompatible with those by Saunders (1994) who found a deep westward export of ISOW with $\sigma_{\theta}>27.80 \mathrm{~kg} \mathrm{~m}^{-3}$ on the basis of 15 months of Eulerian observations, though with abundant cases of current reversals. Region 4 is apparently extremely sensitive to directional shifts of intermediate currents as shown by Schott et al. (1999) on the basis of fluctuations in the track of the deep-reaching North Atlantic Current (NAC).

At the eastern side of region 4, two RAFOS float parks were maintained, one on the exit of each zonal channel of CGFZ (Fig. 8b). The term "park" refers to 
a technology of mooring floats to the bottom for delayed release, as described by Zenk et al. (2000). Although the two parks lie only $200 \mathrm{~km}$ apart, their current fields at the LSW level seem to be very different. The northern park yielded seemingly random results: for example, one float stalling for 10 months and two almost opposite flow directions. The spreading of the floats from the southern park appears much more organized. Two distinct paths are obvious: one with a southward component and another pointing northeastward into the interior of the Iceland Basin. The "competition" of water masses that encounter each other in region 4 has already been described $40 \mathrm{yr}$ ago by Lee and Ellett (1965): "If there is a conflict at this depth, then it is probably between waters by Arctic overflow on the one hand and Mediterranean water on the other." Replacing "Mediterranean water" by "Labrador Sea Water" may describe the conflict more adequately as of today.

In region 5 at the eastern flank of the MAR south of CGFZ, a persistent intermediate western boundary current along the eastern side of the ridge can be confirmed by numerous trajectories. Its speed amounts to $3.9 \pm 2.0 \mathrm{~cm} \mathrm{~s}^{-1}$ based on the ensemble of four floats (one APEX and three RAFOS; Machín et al. 2006). In the past, this branch of modified ISOW with its still strong tracer signal found only limited interest in the literature. It seems to pass CGFZ beneath the inflowing LSW. Its importance for the transport of newly ventilated deep water into the whole West European Basin has been recognized and described more recently by Fleischmann et al. (2001) on the basis of chlorofluorocarbon (CFC-11) observations. Figure 10a shows the remarkable trajectory of a deep (2600 dbar) float that in the beginning of its mission drifted without any perturbation orthogonal to both CGFZ channels and later straight along the bottom topography. The latter evidence is not inconsistent with results by Harvey (1980): there, no signs for an eastward flow in the 3000-m level of CGFZ on the basis of historical hydrographic data were found either, including some 100 occupations of North Atlantic Ocean Weather Ship (OWS) Charlie between 1964 and 1973. Farther south, it is observed that three out of four floats at the LSW level reproduce the tendency to circulate around the Azores Plateau that was noted already by Speer et al. (1999).

Region 6 in the West European Basin is characterized by a sluggish flow southward, slowly renewing the waters with LSW remainders from CGFZ. This lowenergetic area was sampled primarily by MARVOR floats of Eurofloat. One trajectory over $4.5 \mathrm{yr}$ in Fig. $10 \mathrm{c}$ demonstrates the low speed level in region 6 in
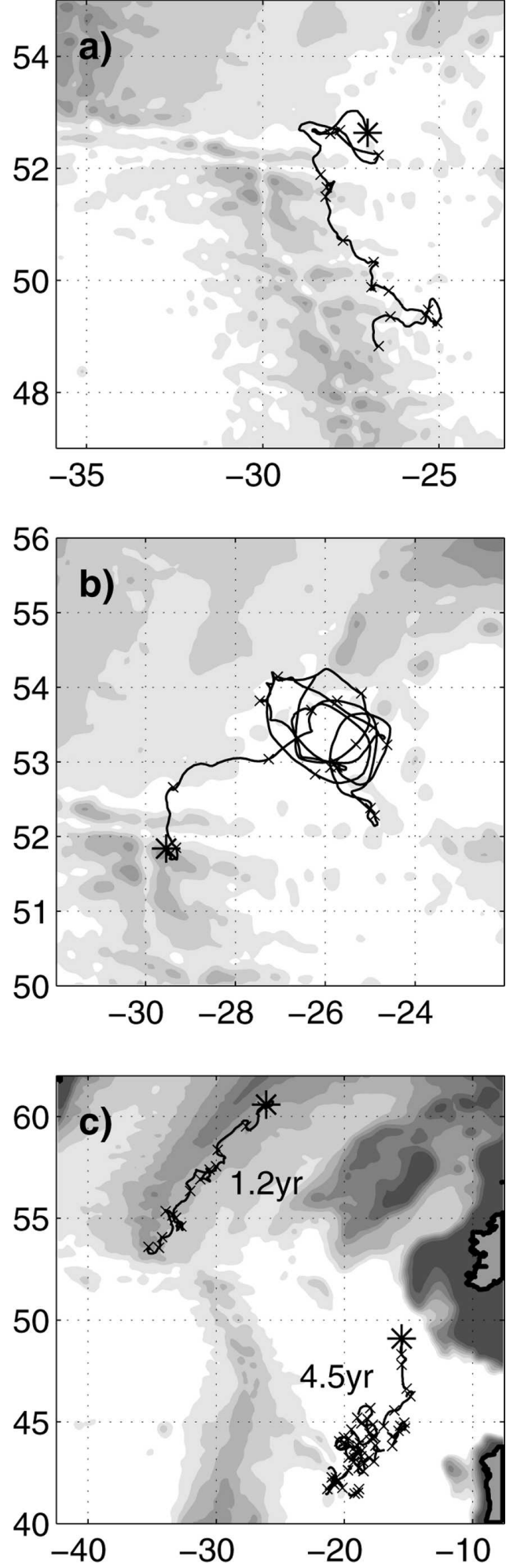

FIG. 10. Same as in Fig. 8, but for (a) SFB RAFOS float east of CGFZ at nominally $2600 \mathrm{dbar}$, (b) SFB RAFOS float (1500 dbar) in a stationary anticyclone, and (c) SFB RAFOS float (1500 dbar) together with Eurofloat MARVOR (1750 dbar). 
contrast to an example near the RR (region 2), where a comparable distance is traveled in a little more than $1 \mathrm{yr}$.

Region 7 southwest of the RP is marked by longliving eddies embedded in a confused background flow. In agreement with results by Shoosmith et al. (2005), these eddies can be almost stationary for many weeks and even months. For instance, one float circulated in an anticyclonic eddy for 444 days in region 7 (Fig. 10b). Five complete revolutions with a diameter of about 150 $\mathrm{km}$ were observed. Four other floats experienced similar schemes superimposed by very little translation in this region. The situation coincides with similar reports about eddies that have been observed repeatedly in the same region (Martin et al. 1998; Pingree and le Cann 1991) at shallower depths but possibly extending to the LSW layer.

Region 8 demonstrates the high eddy activity in the central Iceland Basin-that is, between the contour current regime of region 2 and the western flank of Hatton Bank (HB; Read and Pollard 2001). Figure 8c shows the abundance of slow mean and highly eddy driven motion in the area. Data from two levels (nominally at 1500 and 2600 dbar) confirm the strongly barotropic nature of this region with no significant differences in speed levels between the LSW and the LDW horizons. Typical quantities describing the kinematics of region 8 are included in Table 2. More details on eddy characteristics will be discussed in section 4 .

Region 9 between the southwestern rim of RP and the East Thulian Rise (ETR) contains another question mark of Fig. 3. However, the trajectories in Fig. 8d confirm the (previously not observed) continuation around the plateau. In addition, one trajectory also reveals a slim cyclonic recirculation cell strongly guided by local topography. Its southern flank seems to be guided by the eastward LSW "jet" while the northern boundary current may well be a signature of the Rockall branch of ISOW. Typical speeds within the recirculation regime amount to about $4 \mathrm{~cm} \mathrm{~s}^{-1}$ (Table 2).

Figure 11 displays a sample hydrographic section across the Iceland Basin between the RR and RP. Temperature and salinity distributions in the thermocline indicate strong eddy activities most probably in connection with the meandering of the NAC (Reverdin et al. 2003) - for example, a cyclonic feature near $21^{\circ} \mathrm{W}$ defined by upward displacements of the isotherms over at least the upper $2000 \mathrm{~m}$. They can reach down to the level of LSW with its characteristic salinity minimum (below 34.90) at 1500-2000 dbar and temperatures well above $3.1^{\circ} \mathrm{C}$. It is common (Hansen and Østerhus 2000; Saunders 1994) to define ISOW below a density of $\sigma_{\theta}=$ $27.80 \mathrm{~kg} \mathrm{~m}^{-3}$, also shown in Fig. 11.
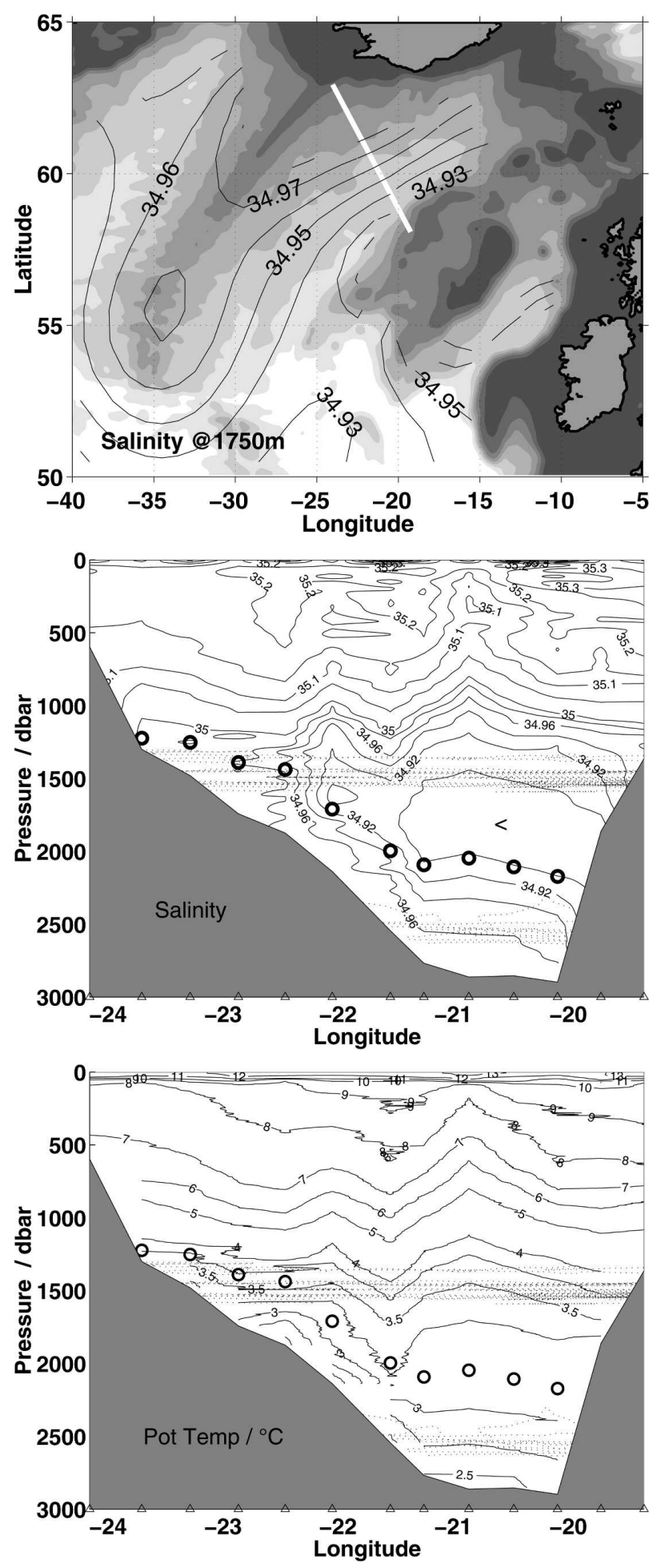

FIG. 11. Hydrographic data from the Iceland Basin. (top) Climatological salinity at 1750-m depth (adapted from Levitus et al. 1994). Bathymetry as in Fig. 1. (middle) Salinity and (bottom) potential temperature from a CTD section (white line in top panel) sampled in August of 2002. All SFB RAFOS float samples north of $60^{\circ} \mathrm{N}$ are projected onto the CTD section and are marked by little dots near the target depths of 1500 and 2600 dbar. Bigger open circles denote the line of $\sigma_{\theta}=27.80 \mathrm{~kg} \mathrm{~m}^{-3}$, and triangular ticks at the bottom indicate locations of CTD stations. 


\section{The mesoscale velocity field}

In this section, the mesoscale variability of the velocity data from the floats is discussed. For this purpose, the Lagrangian integral time scale and eddy kinetic energy (EKE) are the properties to study. A corresponding length scale and diffusivity can be derived from these properties. The underlying theory is that of homogeneous and isotropic turbulence introduced by Taylor (1921) and repeatedly applied in physical oceanography (Krauss and Böning 1987; Lumpkin et al. 2002). With the high data density achieved, the above properties are mapped with unprecedented resolution, extending previous data coverage at middepth (Lumpkin et al. 2002) over almost the entire northeastern Atlantic north of $35^{\circ} \mathrm{N}$. We expect these maps to be especially useful for comparison with computer models. The region features the transition line between the subpolar and subtropical regimes [region $\mathrm{AA}^{\prime}$ in Fig. 19 of Krauss (1986)], which results in readily apparent contrasts of the mesoscale quantities. To relate these integral quantities to individual eddy events, an attempt is made to autodetect eddies according to whether trajectories are "looping" (see the appendix for the method). Because the floats used were designed to drift approximately isobarically, the entire following discussion assumes horizontal motion.

\section{a. Eddy kinetic energy, integral time scale, and derived quantities}

Although studies of EKE occur fairly frequently in the literature, we know of no subsurface maps of this important quantity in the Iceland Basin derived from float observations. Bower (2003) showed such maps in a conference presentation, including the data from this study, but they had to be skipped in the accompanying article (Bower et al. 2002a). Lumpkin et al. (2002) present maps of the Lagrangian integral time and length scales as well as diffusivity, but not of EKE. They do, however, explain the relationship between Lagrangian and Eulerian eddy properties, which may be of interest to the readers who are less familiar with float observations. Their data source already contains early versions of the Eurofloat dataset, but not the SFB floats, so that their maps lack the Iceland Basin. Figure 12 shows a map of the Lagrangian EKE throughout the entire northeastern Atlantic derived from the datasets of the present study (see the appendix for details of the calculation). Overall, values range from below 10 to beyond $100 \mathrm{~cm}^{2} \mathrm{~s}^{-2}$. Relative to the western basin, EKE values are generally lower (typically less than $50 \mathrm{~cm}^{2}$ $\mathrm{s}^{-2}$ ), with three exceptions of increased EKE:

1) The highest values are found in the immediate "im- pact region" of ISOW (our region 1) in the far northeastern corner of the Iceland Basin. Values around $100 \mathrm{~cm}^{2} \mathrm{~s}^{-2}$ are found and are apparently related to variability of the inflowing jet of ISOW.

2) A much larger and better-resolved area is found in the central Iceland Basin at the MC northwest of $\mathrm{HB}$ (region 8). EKE values of circa $80 \mathrm{~cm}^{2} \mathrm{~s}^{-2}$ were observed there, and individual trajectories appear highly "wiggly" to the naked eye (cf. Fig. 8c). The position of this EKE maximum is identical with spots of increased EKE at the sea surface documented by Heywood et al. (1994) and Bersch (1995), both using altimeter data. In combining these with the float measurements, one sees that there is intensified mixing even below the near-surface NAC, which causes the higher EKE in altimetric data. We believe that this area is a sink region for LSW, and that the high EKE is the imprint of its being mixed with surrounding waters, considering the horizontal gradients in the salinity distribution documented in Fig. 11. In particular, there seems to be an influence by ISOW leaking over the Wyville Thomson Ridge (WTR), which is supported by salinity data from CTD lines (cf. Fig. 11).

3) Another maximum of similar amplitude lies in and just west of CGFZ (region 4), but, because this is the limit of the data coverage, nothing can be said about its extension farther west (i.e., upstream along the NAC, which is located at depths in the upper 1000 $\mathrm{m})$. This zone coincides directly with a tongue of increased kinetic energy derived by Krauss and Käse (1984) from near-surface drifters (300-400 cm² $\mathrm{s}^{-2}$ near CGFZ) and by Owens (1991) from SOFAR floats in 700- $\left(440 \mathrm{~cm}^{2} \mathrm{~s}^{-2}\right.$ farther to the west at $\left.39^{\circ} \mathrm{N}, 55^{\circ} \mathrm{W}\right)$ and $2000-\mathrm{m}\left(120 \mathrm{~cm}^{2} \mathrm{~s}^{-2}\right)$ depth. It is apparent that the position of the highly energetic strip is defined by the NAC and the polar front at its northern rim (Rossby 1999). The variability in the immediate vicinity of CGFZ originates from the two water masses LSW and ISOW, tending toward opposite directions through the same gap. Flow reversals are therefore common and cause high EKE. Whether these reversals are triggered by the location of the NAC and whatever happens farther west is subject to ongoing research (Schott et al. 1999).

In the West European Basin, the low EKE of 1-10 $\mathrm{cm}^{2} \mathrm{~s}^{-2}$ reveals this to be a region of sluggish motions, although individual intense eddy events have been observed.

The Lagrangian integral time scale is a measure of the time it takes until the velocity of a float is no longer correlated with itself. With plots of a power spectrum in 

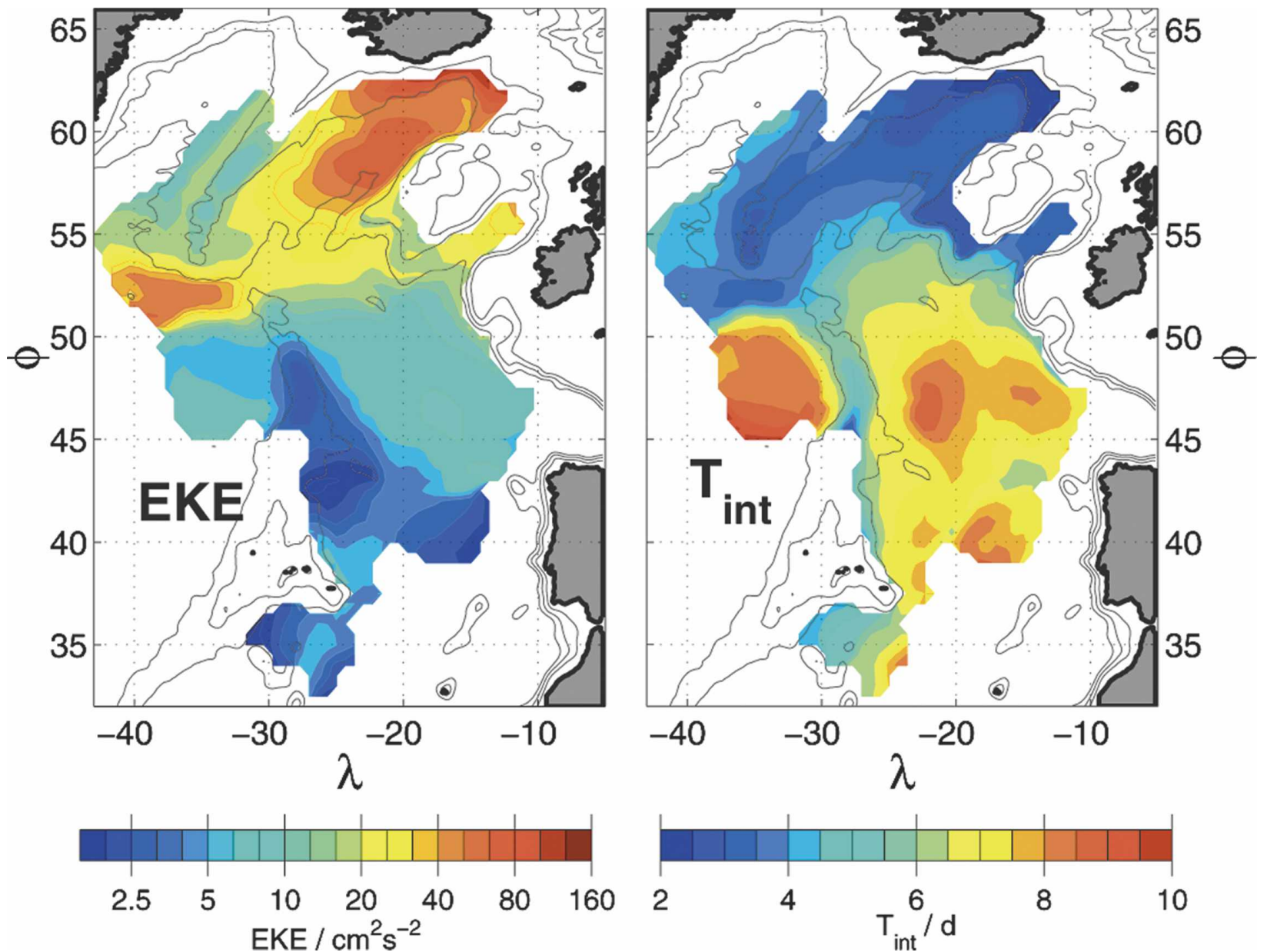

FIG. 12. Lagrangian (left) EKE and (right) integral time scale $\left(T_{\text {int }}\right)$ at nominal depths of $1500-1750 \mathrm{~m}$ in the northeastern Atlantic. High EKE and short time scales in the central and northeastern Iceland Basin are in contrast with low EKE and longer time scales in the European basins and around the Azores. Note that the color scale for the EKE plot is logarithmic. Gray lines show smoothed bathymetry at 1000,2000 , and $3000 \mathrm{~m}$.

mind, one can interpret EKE as an average of the energy level (i.e., the vertical axis), and the integral time scale as an average of the frequencies (i.e., the horizontal axis) that carry significant amounts of energy.

In earlier literature, Lagrangian integral time scales around 10-12 days [the Midocean Dynamics Experiment (MODE); Freeland et al. 1975] and 7 days ("POLYMODE" area; Rossby et al. 1986b) have been reported for the open ocean at depths close to $1500 \mathrm{~m}$. Krauss and Böning (1987) derive values of circa 2-8 days for surface drifters with drogues at 100-m depth.

Figure 12 also shows the Lagrangian integral time scale as computed from the float data of this presentation. The plot contrasts values around 3 days in the Iceland Basin to those around 8 days in the West $\mathrm{Eu}$ ropean Basin farther south. The latter agrees well with results by Lumpkin et al. (2002), although the extension of the dataset with the SFB floats into the Iceland Basin completes the side-by-side view of the two basins. Within the Iceland Basin, the time scales reach their lowest values of $\sim 2$ days in the northeastern part, north of HB. Because the data are low-pass filtered with a cutoff period at 3 days (see the appendix), the actual values are likely to be even smaller. As expected, the area of the shortest time scales coincides with that of highest EKE, again indicating strong turbulent activity in the area. In general, one would expect lower values in the subpolar areas, since the nature of the flow is more barotropic there, and thus the influence of the more rapidly changing near-surface motions is stronger at greater depths. However, the sudden drop at the line connecting CGFZ with the RP-where the subpolar and subtropical gyres meet-remains remarkable.

The longer time scales in the West European Basin farther south again confirm the impression of a more quiescent regime, which misses variability at the high- 

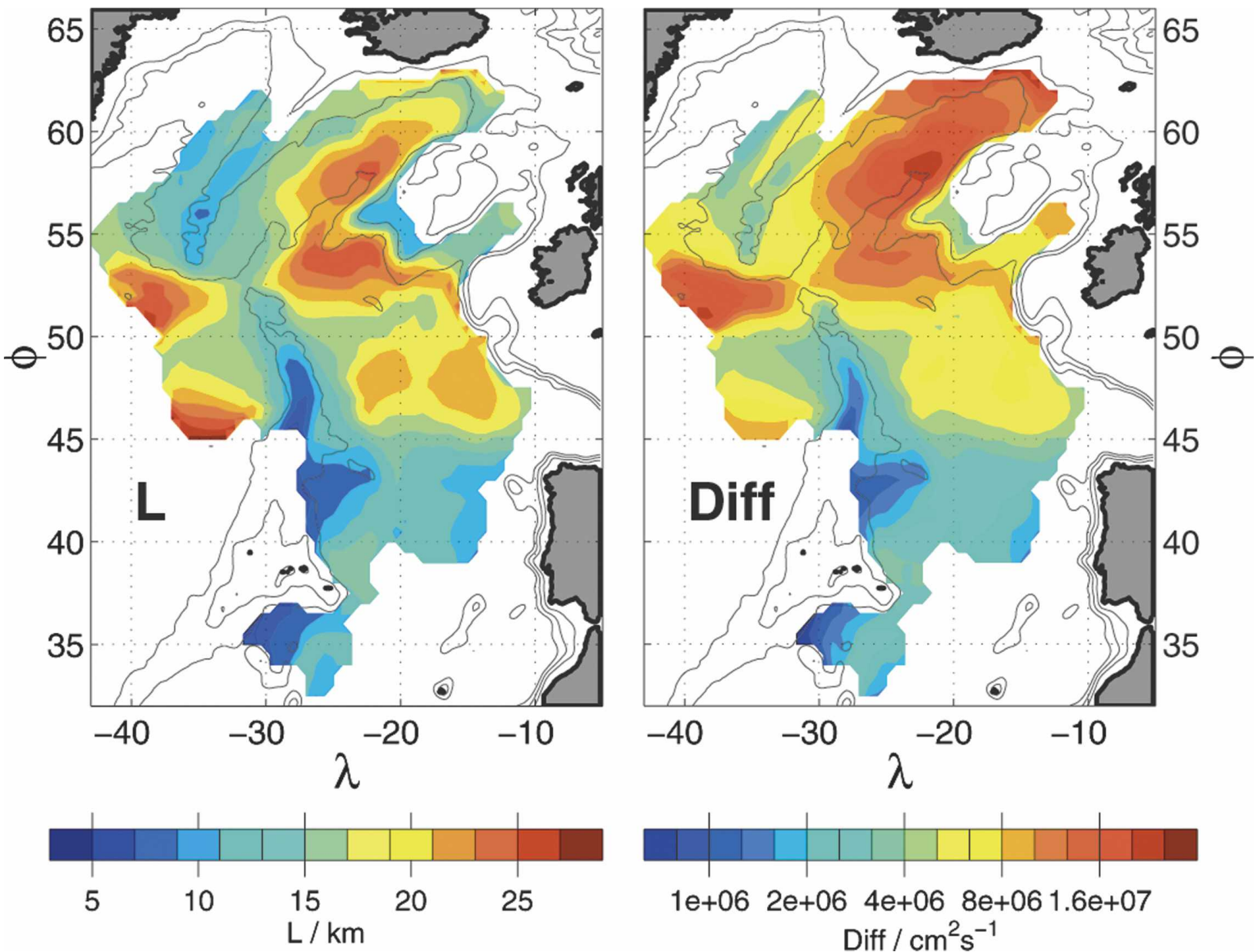

FIG. 13. Same as in Fig. 12, but for Lagrangian (left) length scale (L) and (right) horizontal diffusivity (Diff). The longest length scales are found southwest of RP and west of CGFZ; length scales directly above the MAR are shortest. Highest diffusivities are found in the central Iceland Basin, whereas the West European Basin typically has low values. Note that the diffusivity color scale is logarithmic.

frequency part of the spectrum when compared to the subpolar areas.

The few values available from the western basin southwest of CGFZ (i.e., in the subtropical gyre) are around 8 days as well, not at disagreement with the early observations of MODE and POLYMODE. The short time scales following the MAR system show how bathymetry confuses the flow one would otherwise see, quickly reducing (temporal) autocorrelation as the trajectories move from one obstacle to the next. This can be seen at depths significantly shallower than the depths of the obstacles themselves.

Knowing EKE and the time scale, one can compute a corresponding length scale and a horizontal diffusivity estimate from these (cf. the appendix). The Lagrangian length scale can be interpreted as a representative eddy size and is of similar order as the first baroclinic Rossby radius. Figure 13 shows this length scale calculated accordingly for our dataset, again extensively enlarging the database relative to that of Lumpkin et al. (2002). Throughout the entire study area, the Lagrangian length scale is on the order of $10 \mathrm{~km}$, with highest values of 20-25 km west of CGFZ and around the RP. The maximum southwest of the RP coincides with region 7 where several large anticyclones were observed. On either side of the MAR, values are $\sim 10-15 \mathrm{~km}$, and the shortest length scales of about $5 \mathrm{~km}$ are observed directly north of the Azores Plateau.

Because the meaning of the horizontal diffusivity estimate is strongly restricted by the assumptions of homogeneity and isotropy of the eddy field, it may only be interpreted safely in the interior parts of the basins. Figure 13 also shows the horizontal diffusivity. The general distribution of this quantity follows the EKE pattern, because EKE is subject to larger spatial fluctuations in the area than the time scale. Within the Iceland Basin, its spatial distribution is complex, spanning a range of $\sim 5 \times 10^{6}-22 \times 10^{6} \mathrm{~cm}^{2} \mathrm{~s}^{-1}$. The highest values 
are observed in the central Iceland Basin northwest of HB (region 8), confirming that this is the primary location for transformation of water masses at middepth in the northeastern Atlantic. Another maximum of nearly equal amplitude is located west of CGFZ (see discussion of EKE above). Virtually the entire West European Basin is characterized by very low values $(<8$ $\left.\times 10^{6} \mathrm{~cm}^{2} \mathrm{~s}^{-1}\right)$.

\section{b. Coherent eddies}

As discussed in the previous section, the Iceland $\mathrm{Ba}-$ sin features high EKE and short time scales, indicative of enhanced turbulent mixing. A closer look at discrete eddies in the area at shallower depths has been performed by Shoosmith et al. (2005), where trajectories with looping parts were selected by visual inspection. Their dataset is reported to contain 19 anticyclones versus 18 cyclones in the Iceland Basin [cyclone/anticyclone (c/a) ratio of 0.9] and 12 anticyclones and 7 cyclones in the West European Basin (c/a of 0.6). For the present study, an automatic detection scheme has been applied to identify looping trajectories (cf. the appendix). Two completed revolutions are required to be counted as an eddy.

An analysis of SFB and EUROFLOAT trajectories confined to the Iceland Basin revealed 37 cyclones and 16 anticyclones using this method (c/a of 2.3). Of a total of 15968 days of trajectory data, 2222 (13.9\%) were spent in cyclones, and 955 (6.0\%) were spent in anticyclones. Although these percentages are obviously sensitive to the criteria applied during eddy detection, we expect the ratio of cyclone days to anticyclone days $(>2: 1)$ to be independent of these details. In the West European Basin, 43 cyclones and 28 anticyclones were identified (c/a of 1.5) among 23758 days of trajectory data. They were distributed among 1512 (6.4\%) cyclone days and $1350(5.7 \%)$ anticyclone days, respectively. The ratio of cyclone to anticyclone days is therefore down to almost 1:1. Figure 14 shows how the mean eddy periods are distributed. Especially at the shortest periods resolved (i.e., less than 10 days), the cyclones outnumber the anticyclones significantly in both basins. In relation to the total amount of data, the cyclonic eddies are significantly more abundant in the Iceland Basin than in the West European Basin. Relative to the findings by Shoosmith et al. (2005), more cyclonic vortices are found in both basins. A possible explanation is that the automatic detection also accepts quickly advected eddies, the trajectories of which are cusps rather than closed loops and therefore are rejected by Shoosmith et al. (2005). It could be that these are more common in high-frequency eddies and therefore bias the direct comparison in favor of cyclones. Paillet

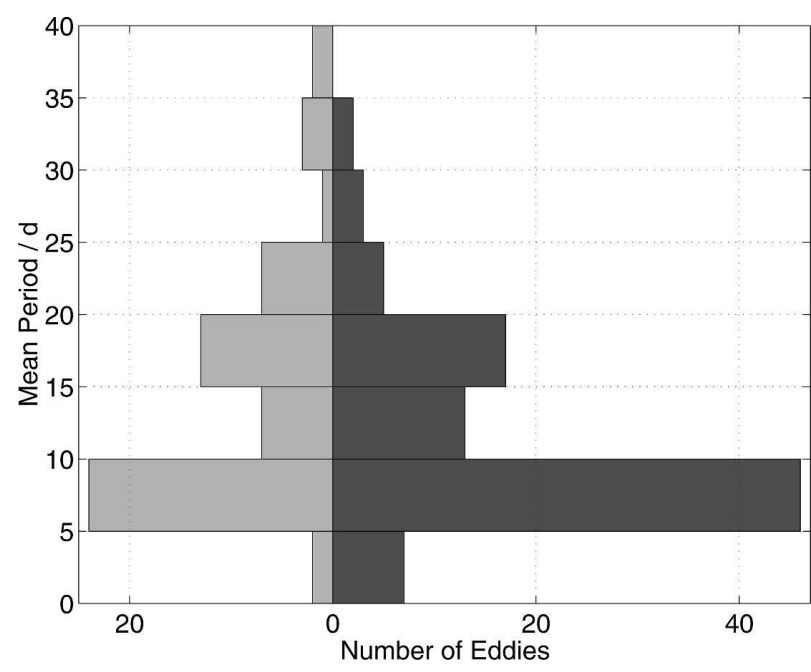

FIG. 14. Histogram of mean eddy periods for autodetected eddies in the entire study area. Data on anticyclones are in light gray, and those on cyclones are in dark gray. At short periods ( $<10$ days), the cyclones outnumber the anticyclones considerably.

(1999) also found more anticyclones than cyclones in the Central Water using hydrographic section data, but his data do not cover the subpolar Iceland Basin, making a direct comparison difficult.

Figure 15 shows spectra of the float velocity data, separated into Iceland and West European Basins. For each basin, separate spectra are displayed for the entire dataset and for the extracted eddy segments within the trajectories. At first glance, it is obvious that the Iceland Basin contains a higher energy level by about one order of magnitude, as was already seen in the EKE map (Fig. 12). In addition, the cyclones are more energetic (by a factor of about 4), particularly at high frequencies (beyond 0.1 day $^{-1}$ ), than are the remaining data within both basins. In the Iceland Basin, where they were found to be common, these cyclones seem to play an important role in watermass transformation. Their outstanding energy levels at short time scales may cause much of the remarkable difference between the subpolar and subtropical gyres as pointed out in the previous paragraphs, in particular because they seem to be more abundant in the former when compared with the total amount of data. A similar conclusion was drawn by Boebel et al. (2003), emphasizing the role of cyclones in mixing versus the well-known anticyclonic Agulhas rings off South Africa.

\section{Conclusions}

In this contribution, float trajectories from the entire northeastern Atlantic Ocean between Iceland and the 


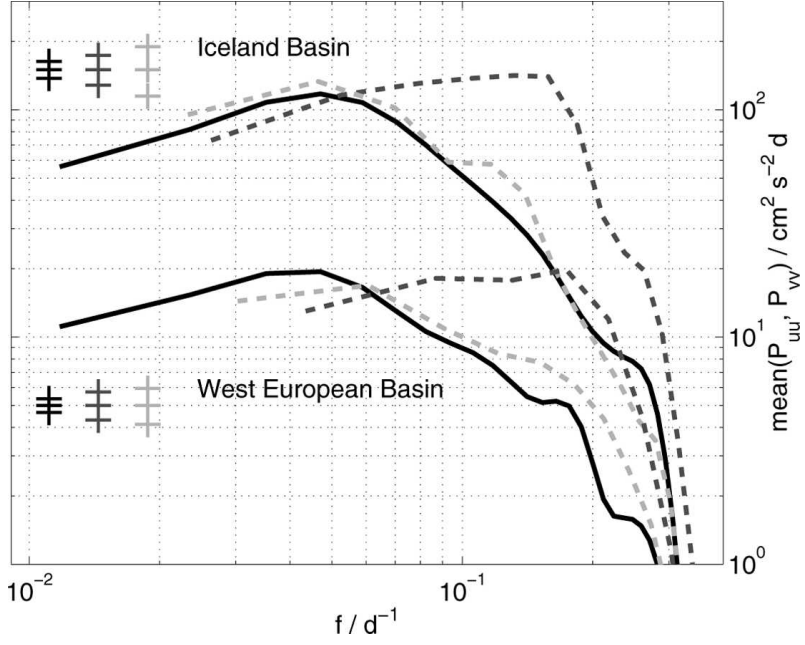

FIG. 15. Lagrangian velocity spectrum of trajectories within the Iceland Basin (upper bundle of lines) and West European Basin (lower lines). The lines show spectra of the entire datasets (black solid) and of only the eddy segments (light gray dashed are anticyclones; dark gray dashed are cyclones). In both basins, the cyclones carry significantly more energy at short periods ( $<10$ days) when compared with the anticyclones or the total mean. In addition, motions in the Iceland Basin are more energetic than in the West European Basin by almost an order of magnitude. Error bars indicate $95 \%$ confidence limits. A low-pass filter with a cutoff period of 3 days was applied to the trajectories, causing the rapid decrease at the right edge.

Azores are analyzed. The dataset is from intermediate and deeper depths (1500-2600 dbar) with high data density throughout its large horizontal extent, thereby enlarging our knowledge from previous publications (Böning 1988; Bower et al. 2002a; Lumpkin et al. 2002; Faure and Speer 2005). The flow regimes of both the subpolar and subtropical gyres are clearly controlled at depth by local bottom topography. In the north, two driving water masses (Labrador Sea and IcelandScotland Overflow Waters) are involved in the cyclonic circulation spanning the entire Iceland Basin. The southern parts are best described by a deep western boundary current along the Mid-Atlantic Ridge, and a region of sluggish motion in the inner West European Basin where Mediterranean and Labrador Sea Waters compete.

Nine different subregions of the eastern basins with individually different kinematic characteristics are identified, following the pathways of LSW and ISOW through the eastern basins. Areas of strong and highly stable mean currents are found to stand side by side with regimes of intense variability or of generally slow motions. The role of the Charlie-Gibbs and Bight Fracture Zones as exchange regions for water between the eastern and western basins across the MAR (Bower et al. 2002a) could be confirmed by selected pathways of floats and in sediment records. Statistical properties of the mesoscale field coincide with observations by Lumpkin et al. (2002). Significant improvements are made by adding the large SFB dataset from the subpolar area and mapping properties with a bottom-following interpolation scheme (Davis 1998). In the Iceland Basin, areas of intense mixing and high-frequency motions [EKE $\approx O\left(100 \mathrm{~cm}^{2} \mathrm{~s}^{-2}\right) ; T_{\mathrm{int}} \leq 3$ days] are found, which contrast sharply with values from the subtropics [EKE $\approx O\left(10 \mathrm{~cm}^{2} \mathrm{~s}^{-2}\right) ; T_{\mathrm{int}} \approx 8$ days].

A mostly automatic identification scheme for eddies in the trajectories was applied, the findings of which emphasize the role of cyclonic eddies as carriers of high energy at short time scales, and therefore possibly as major mixing agents.

To conclude, the pathways of ISOW suggested with caveats in Fig. 3 (Hansen and Østerhus 2000) could be directly observed and extended. The eddy field associated with these motions is described by maps spanning the entire northeast Atlantic, and the combined look at the mean field and the mixing reveals how and where in the area the water masses involved are subject to transformation processes.

As an outlook, one may expect the Argo array to report sufficient amounts of data to monitor mean currents and hydrographic variability, with the exception that these instruments do not resolve mesoscale motions because of their reduced temporal resolution. A topic for future studies could be the strength of the influence of the meandering North Atlantic Current system. Data from the MAR region suggest that these processes of the upper-water column have a significant imprint even at the depths under consideration here, in particular in the more barotropic subpolar area.

Acknowledgments. SFB 460 is funded by the Deutsche Forschungsgemeinschaft (DFG, Bonn, Germany). Detailed information is available online at www.ifmgeomar.de/index.php?id $=575 \& \mathrm{~L}=1$. Eurofloat was funded as a MAST-2 program of the European Commission under contract MAS2CT940103 (see online at www. ifremer.fr/lpo/eurofloat/). Data from profiling floats are collected and made freely available by the International Argo Project and the national programs that contribute to it (see online at www.argo.ucsd.edu and argo.jcommops. org). Argo is a pilot program of the Global Ocean Observing System. In particular, data from the project GyroScope are used. GyroScope was part of the Fifth Framework Programme of the European Commission defined per Contract EVK2 CT-2000-00087 (www. ifremer.fr/lpo/gyroscope/; www.coriolis.eu.org/cde/ projects/gyroscope.htm). Contributing work and advice 
by the following colleagues and friends are highly appreciated: Lars Böhme, Rolf Käse, and Gerold Siedler. In addition, the authors honor the work by the ship crews and their expertise during the research cruises with $\mathrm{Me}$ teor and Poseidon.

\section{APPENDIX}

\section{Methods and Computational Details}

\section{a. Data processing}

SFB and Eurofloat data were processed using the software package "ARTOA," introduced by Menzel (1995) and improved recently by O. Boebel et al. (2002, personal communication). Position data were obtained once per day, but the trajectory data were filtered with a low-pass Butterworth filter with a cutoff period of 3 days to remove submesoscale noise. All trajectories were inspected by eye to remove obvious errors (e.g., spikes or positions over shallow obstacles). Where information on clock drifts could not be deduced directly from the raw data, these were adjusted to make the floats come close to their launch and resurfacing positions.

\section{b. Calculation of the integral properties}

The integral quantities discussed in section 4 were calculated using the Drifter Analysis (DANA) software package presented by Lankhorst (2003). ${ }^{\mathrm{A} 1}$ Trajectories were split up in overlapping windows of 3 months in length. This period seems to be a good compromise to be longer than the mesoscale and not to interfere with annual variability, and, because of the cycle of the MARVOR floats (interruptions every 90 days), it enables all trajectories to be processed in the same fashion. For these segments, Lagrangian EKE and integral time scales were computed and mapped with an interpolation scheme that follows bathymetry (Fig. 12). The idea of this interpolation scheme is presented by Davis (1998) and is based on a generalized distance between two points, which is calculated from their geometric distance and the difference in barotropic potential vorticity. Decorrelation scales of $200 \mathrm{~km}$ and $0.1[\lambda$ and $\phi$ of Eq. (11b) in Davis (1998), respectively] were applied here. Taking bathymetry into account during mapping has the advantage that properties from boundary regimes are kept separate from the interior while keeping decorrelation lengths in the interior large to increase the number of degrees of freedom. Length scales and

\footnotetext{
${ }^{\text {A1 }}$ The DANA software is freely available from M. Lankhorst upon request.
}

diffusivities were calculated for each trajectory segment from EKE and time scales and were mapped with the same interpolation scheme (Fig. 13). The calculation of the quantities was carried out as follows.

Let the horizontal Lagrangian velocity $\mathbf{u}=(u, v)$ measured by a float be separated into its mean $\overline{\mathbf{u}}$ and deviations $\mathbf{u}^{\prime}$ thereof, as in

$$
u=\bar{u}+u^{\prime} \quad \text { and } \quad v=\bar{v}+v^{\prime} .
$$

Then, the eddy kinetic energy is defined as

$$
\mathrm{EKE}=\frac{1}{2}\left(\overline{u^{\prime 2}}+\overline{v^{\prime 2}}\right)
$$

and is simply computed from the variances $\overline{u^{\prime 2}}$ and $\overline{v^{\prime 2}}$ of the velocity components. All of the following calculations were carried out for both $u$ and $v$ components, although only $u$ is shown for simplicity. In the figures, means of both components are shown. With the (normalized) autocorrelation of $u$ at time lag $\tau$ written as $R_{u}(\tau)$, the Lagrangian integral time scale is defined as

$$
T_{\mathrm{int}, u}=\int_{0}^{\infty} R_{u}(\tau) d \tau .
$$

It is a measure of the time it takes until the velocity of a float is not correlated with itself anymore. Here, the integration was carried out only up to the first zero crossing of $R_{u}(\tau)$. Different calculation techniques are discussed by Lumpkin et al. (2002).

The Lagrangian length scale $L_{u}$ is a measure of the distance a float travels during the time $T_{\mathrm{int}, u}$, that is, a typical spatial decorrelation scale or eddy size:

$$
L_{u}=\sqrt{\overline{\overline{u^{\prime 2}}}} T_{\mathrm{int}, u} .
$$

Horizontal diffusivity is estimated by

$$
D_{u}=\overline{u^{\prime 2}} T_{\mathrm{int}, u},
$$

provided that one is looking at motions on time scales significantly longer than $T_{\mathrm{int}, u}$ itself (random walk regime as opposed to initial dispersion; cf. Taylor 1921). As mentioned in the main text, this is only true if the eddy field is reasonably homogeneous and isotropic.

\section{c. Eddy detection algorithm}

Searching for eddies as looping trajectories by visual inspection (e.g., Shoosmith et al. 2005) is obviously very time consuming and is subject to human error. An automatic detection routine was developed and was applied to data from the Cape of Good Hope Experiments (KAPEX) project (off southern Africa) by Boebel et al. (2003), searching for a threshold curvature over fixed periods of time. To avoid having to define curvature and time manually (which are likely to vary with EKE and typical time scales, depending on location), a different approach was developed by Lankhorst 
(2003) and was applied here. This algorithm is also included in the DANA software. It uses overlapping trajectory segments of different lengths (here: 10, 20, 40, and 85 days), each of which is detrended and smoothed before a second-order autoregressive (AR2) process is fit to the velocity data. This type of stochastic processes describes a harmonic oscillator with a random whitenoise forcing, according to the following equation for a variable $z$ given at discrete, equally spaced times $t_{n}=t_{0}$ $+n \Delta_{t}$ :

$$
z\left(t_{n}\right)=\phi_{1} z\left(t_{n-1}\right)+\phi_{2} z\left(t_{n-2}\right)+\varepsilon
$$

The fit returns the two constant coefficients (hence, second order) $\phi_{1,2}$ and the variance of the stochastic forcing $\varepsilon$. The coefficients can be transformed into two time scales (frequency and damping of an exponentially damped sinusoidal); a detailed description can be found in (Box et al. 1994). A trajectory segment is then considered to be part of an eddy if the following criteria apply:

1) the frequencies obtained from the AR2 coefficients are real (i.e., oscillating behavior as opposed to exponential decline) for both $u$ and $v$ velocity components,

2) the $u$ and $v$ frequencies are (almost) equal,

3) the damping time scale is greater than a threshold value, which is based on the frequency,

4) the damping time scales are (almost) equal for $u$ and $v$,

5) the AR2 fit explains most of the actual variance,

6) the motion features at least two complete revolutions, and

7) the phase lag between $u$ and $v$ is near $90^{\circ}$.

This detection algorithm has been compared with the visual results by Shoosmith et al. (2005). Limiting this comparison to eddies with at least three revolutions, the automatic algorithm identifies 46 of $57(81 \%)$ eddies found by Shoosmith et al. (2005). The entire comparison and details of the detection scheme are documented by Lankhorst (2005, manuscript submitted to J. Atmos. Oceanic Technol.)

\section{REFERENCES}

Bersch, M., 1995: On the circulation of the northeastern North Atlantic. Deep-Sea Res., 42A, 1583-1607.

Boebel, O., J. Lutjeharms, C. Schmid, W. Zenk, T. Rossby, and C. Barron, 2003: The Cape Cauldron: A regime of turbulent inter-ocean exchange. Deep-Sea Res., 50B, 57-86.

Böning, C. W., 1988: Characteristics of particle dispersion in the North Atlantic: An alternative interpretation of SOFAR float results. Deep-Sea Res., 35A, 1379-1385.

Bower, A., 2003: Directly-measured mid-depth circulation in the northeastern North Atlantic. Geophysical Research Abstracts, Vol. 5, Nice, France, European Geophysical Society, No. 05984. [Available online at http://www.cosis.net/ abstracts/EAE03/05984/EAE03-J-05984.pdf.]
- and Coauthors, 2002a: Directly measured mid-depth circulation in the northeastern North Atlantic Ocean. Nature, 419, 603-607.

- N. Nerra, and I. Ambar, 2002b: Structure of the Mediterranean Undercurrent and Mediterranean Water spreading around the southwestern Iberian Peninsula. J. Geophys. Res., 107, 3161, doi:10.1029/2001JC001007.

Box, G. E. P., G. M. Jenkins, and G. C. Reinsel, 1994: Time Series Analysis: Forecasting and Control. 3d ed. Prentice Hall, 598 pp.

Davis, R. E., 1998: Preliminary results from directly measuring middepth circulation in the tropical and South Pacific. J. Geophys. Res., 103, 24 619-24 639.

during the 1990s. Ocean Circulation and Climate, G. Siedler, J. Church, and J. Gould, Eds., Academic Press, 123-139.

Dickson, R. R., and J. Brown, 1994: The production of North Atlantic Deep Water: Sources, rates, and pathways. J. Geophys. Res., 99, 12 319-12 341.

Faure, V., and K. Speer, 2005: Labrador Sea Water circulation in the Northern North Atlantic Ocean. Deep-Sea Res., 52B, $565-581$.

Fischer, J., and F. A. Schott, 2002: Labrador Sea Water tracked by profiling floats-From the boundary current into the open North Atlantic. J. Phys. Oceanogr., 32, 573-584.

Fleischmann, U., H. Hildebrandt, A. Putzka, and R. Bayer, 2001: Transport of newly ventilated deep water from the Iceland Basin to the West European Basin. Deep-Sea Res., 48A, 1793-1819.

Freeland, H. J., P. B. Rhines, and T. Rossby, 1975: Statistical observations of the trajectories of neutrally buoyant floats in the North Atlantic. J. Mar. Res., 33, 383-404.

Hansen, B., and S. Østerhus, 2000: North Atlantic-Nordic seas exchanges. Progress in Oceanography, Vol. 45, Pergamon, 109-208.

Harvey, J. G., 1980: Deep and bottom water in the Charlie-Gibbs Fracture Zone. J. Mar. Res., 38, 173-182.

Helland-Hansen, B., and F. Nansen, 1909: The Norwegian SeaIts physical oceanography based upon the Norwegian researches 1900-1904. Report on Norwegian Fishery and Marine Investigations, J. Hjort, Ed., Vol. 2, Royal Department of Trade, Navigation, and Fisheries, 390 pp.

Heywood, K. J., E. L. McDonagh, and M. A. White, 1994: Eddy kinetic energy of the North Atlantic subpolar gyre from satellite altimetry. J. Geophys. Res., 99, 22 525-22 539.

Hinrichsen, H.-H., M. Rhein, R. H. Käse, and W. Zenk, 1993: The Mediterranean Water tongue and its chlorofluoromethane signal in the Iberian Basin in early summer 1989. J. Geophys. Res., 98, 8405-8412.

Krauss, W., 1986: The North Atlantic Current. J. Geophys. Res., 91, 5061-5074

, 1995: Currents and mixing in the Irminger Sea and in the Iceland Basin. J. Geophys. Res., 100, 10 851-10 871.

— energy in the eastern North Atlantic. J. Geophys. Res., 89, 3407-3415.

_ , and C. W. Böning, 1987: Lagrangian properties of eddy fields in the northern North Atlantic as deduced from satellite-tracked buoys. J. Mar. Res., 45, 259-291.

Lankhorst, M., 2003: Klassifizierung charakteristischer Eigenschaften von Float-Trajektorien in unterschiedlichen dynamischen Regionen (Classification of characteristic properties of float trajectories in different dynamic regions). Diploma 
thesis, Mathematisch-Naturwissenschaftliche Fakultät, Christian-Albrechts-Universität, Kiel, Germany, 84 pp.

—, M. Nielsen, and W. Zenk, cited 2004: RAFOS float trajectories from the Labrador Sea water level in the Iceland Basin 1997-2003. [Available online at http://www.ifm-geomar.de/ index.php?id $=999 \& \mathrm{~L}=1$.]

Lee, A., and D. Ellett, 1965: On the contribution of overflow water from the Norwegian Sea to the hydrographic structure of the North Atlantic Ocean. Deep-Sea Res., 12, 129-142.

Levitus, S., R. Burgett, and T. P. Hoyer, 1994: Salinity. Vol. 3, World Ocean Atlas 1994, NOAA Atlas NESDIS 3, 99 pp.

Lorbacher, K., 2000: Niederfrequente Variabilität meridionaler Transporte in der Divergenzzone des nordatlantischen Subtropen- und Subpolarwirbels-Der WOCE-Schnitt A2 (Lowfrequency variability of the meridional transports in the divergence zone of the North Atlantic subtropical and subpolar gyres-The WOCE transect A2). Bundesamt für Seeschiffahrt und Hydrographie Rep. 22, Hamburg, Germany, 156 pp.

Lumpkin, R., and K. Speer, 2003: Large-scale vertical and horizontal circulation in the North Atlantic Ocean. J. Phys. Oceanogr., 33, 1902-1920.

— - A.-M. Treguier, and K. Speer, 2002: Lagrangian eddy scales in the northern Atlantic Ocean. J. Phys. Oceanogr., 32, 2425-2440.

Machín, F., U. Send, and W. Zenk, 2006: Intercomparing drifts from RAFOS and profiling floats in the deep western boundary current along the Mid-Atlantic Ridge. Sci. Mar., in press.

Martin, A. P., I. P. Wade, K. J. Richards, and K. J. Heywood, 1998: The PRIME eddy. J. Mar. Res., 56, 439-462.

McCartney, M. S., 1992: Recirculating components to the deep boundary current of the northern North Atlantic. Progress in Oceanography, Vol. 29, Pergamon, 283-383.

McCave, I. N., and B. E. Tucholke, 1986: Deep current-controlled sedimentation of the western North Atlantic. The Geology of North America, P. R. Vogt, Ed., Vol. M, Geological Society of America, 451-468.

Menzel, M., 1995: Entwicklung eines Programmpaketes zur Datenaufbereitung, Berechnung und Visualisierung von Floattrajektorien (Development of a program package for data preparation, calculation, and visualization of float trajectories). Diploma thesis, Fachhochschule, Fachbereich Informatik und Elektrotechnik (University of Applied Sciences, Faculty of Computer Science and Electrical Engineering), Kiel, Germany, $274 \mathrm{pp}$.

Ollitrault, M., 1999: MARVOR floats reveal intermediate circulation in the western equatorial and tropical South Atlantic $\left(30^{\circ} \mathrm{S}\right.$ to $\left.5^{\circ} \mathrm{N}\right)$. Int. WOCE Newsl., No. 34, 7-10.

Owens, W. B., 1991: A statistical description of the mean circulation and eddy variability in the northwestern Atlantic using SOFAR floats. Progress in Oceanography, Vol. 28, Pergamon, 257-303.

Paillet, J., 1999: Central water vortices of the eastern North Atlantic. J. Phys. Oceanogr., 29, 2487-2503.

—, M. Arhan, and M. S. McCartney, 1998: Spreading of Labrador Sea Water in the eastern North Atlantic. J. Geophys. Res., 103, 10 223-10 239.

Pingree, R. D., and B. le Cann, 1991: Drifting buoy in the field of flow of two eddies on East Thulean Rise (Northeast Atlantic). J. Geophys. Res., 96, 16 759-16 777.

Read, J. F., and R. T. Pollard, 2001: A long-lived eddy in the Iceland Basin 1998. J. Geophys. Res., 106, 11 411-11 421.

Reverdin, G., P. P. Niiler, and H. Valdimarsson, 2003: North Atlantic Ocean surface currents. J. Geophys. Res., 108, 3002, doi:10.1029/2001JC001020.
Rhein, M., and Coauthors, 2002: Labrador Sea Water: Pathways, CFC inventory, and formation rates. J. Phys. Oceanogr., 32, 648-665.

Rossby, T., 1988: Five drifters in a Mediterranean salt lens. DeepSea Res., 35, 1653-1663.

_ 1999: On gyre interractions. Deep-Sea Res., 46B, 139-164.

- D. Dorson, and J. Fontaine, 1986a: The RAFOS system. $J$. Atmos. Oceanic Technol., 3, 672-679.

- J. Price, and D. Webb, 1986b: The spatial and temporal evolution of a cluster of SOFAR floats in the POLYMODE Local Dynamics Experiment (LDE). J. Phys. Oceanogr., 16, 428-442.

Saunders, P. M., 1987: Flow through Discovery Gap. J. Phys. Oceanogr., 17, 631-643.

_ 1994: The flux of overflow water through the Charlie-Gibbs Fracture Zone. J. Geophys. Res., 99, 12 343-12 355.

Schmitz, W. J., Jr., 1995: On the interbasin-scale thermohaline circulation. Rev. Geophys., 33, 151-173.

Schott, F. A., L. Stramma, and J. Fischer, 1999: Interaction of the North Atlantic Current with the deep Charlie Gibbs Fracture Zone throughflow. Geophys. Res. Lett., 26, 369-372.

_, R. Zantopp, L. Stramma, M. Dengler, J. Fischer, and M. Wibaux, 2004: Circulation and deep-water export at the western exit of the subpolar North Atlantic. J. Phys. Oceanogr., 34, 817-843.

Shoosmith, D. R., P. L. Richardson, A. S. Bower, and H. T. Rossby, 2005: Discrete eddies in the northern North Atlantic as observed by looping RAFOS floats. Deep-Sea Res., 52B, $627-650$.

Sparrow, M., O. Boebel, V. Zervakis, W. Zenk, A. CantosFiguerola, and W. J. Gould, 2002: Two circulation regimes of the Mediterranean outflow revealed by Lagrangian measurements. J. Phys. Oceanogr., 32, 1322-1330.

Speer, K. G., J. Gould, and J. LaCasce, 1999: Year-long float trajectories in the Labrador Sea Water of the eastern North Atlantic Ocean. Deep-Sea Res., 46B, 165-179.

Srivastava, S. P., D. Voppel, and B. Tucholke, 1988: Geophysical Atlas of the North Atlantic between $50^{\circ}$ to $72^{\circ} \mathrm{N}$ and $0^{\circ}$ to $65^{\circ} \mathrm{W}$. Deutsches Hydrographisches Institut, 12 pp. plus charts.

Swift, D. D., and S. C. Riser, 1994: RAFOS floats: Defining and targeting surfaces of neutral buoyancy. J. Atmos. Oceanic Technol., 11, 1079-1092.

Sy, A., M. Rhein, J. R. N. Lazier, K. P. Koltermann, J. Meincke, A. Putzka, and M. Bersch, 1997: Surprisingly rapid spreading of newly formed intermediate waters across the North Atlantic Ocean. Nature, 386, 675-679.

Taylor, G. I., 1921: Diffusion by continuous movements. Proc. London Mathematical Society, Vol. 20, London, United Kingdom, London Mathematical Society, 196-212.

van Aken, H. M., and C. J. de Boer, 1995: On the synoptic hydrography of intermediate and deep water masses in the Iceland Basin. Deep-Sea Res., 42A, 165-189.

— northeastern North Atlantic Ocean: The NANSEN project. Progress in Oceanography, Vol. 38, Pergamon, 297-346.

Worthington, L. V., and G. H. Volkmann, 1965: The volume transport of the Norwegian Sea overflow water in the North Atlantic. Deep-Sea Res., 12, 667-676.

Zenk, W., A. Pinck, S. Becker, and P. Tillier, 2000: The float park: A new tool for a cost-effective collection of Lagrangian time series with dual release RAFOS floats. J. Atmos. Oceanic Technol., 17, 1439-1443. 